\title{
Article \\ A Novel Approach of Integrating Natural Language Processing Techniques with Fuzzy TOPSIS for Product Evaluation
}

\author{
Tianxiong Wang
}

Citation: Wang, T. A Novel Approach of Integrating Natural Language Processing Techniques with Fuzzy TOPSIS for Product Evaluation. Symmetry 2021, 14, 120. https://doi.org/10.3390/ sym14010120

Academic Editor: José Carlos

R. Alcantud

Received: 12 October 2021 Accepted: 15 November 2021 Published: 10 January 2022

Publisher's Note: MDPI stays neutral with regard to jurisdictional claims in published maps and institutional affiliations.

Copyright: (C) 2022 by the author Licensee MDPI, Basel, Switzerland. This article is an open access article distributed under the terms and conditions of the Creative Commons Attribution (CC BY) license (https:// creativecommons.org/licenses/by/ $4.0 /)$
Department of Design, School of Art, Anhui University, Hefei 230601, China; 21118@ahu.edu.cn
Abstract: Product designers need to fully understand consumers' emotional preferences and responses for product forms to improve products. However, users and designers have different understandings and concepts in the product evaluation process, which will lead to cognitive asymmetry in the product design and evaluating process. This phenomenon prevents designers to grasp users' needs, increasing the risk of product development failure. To this end, this paper proposes a product evaluation method that combines natural language processing techniques and fuzzy multi-criteria decision-making into a new integrated way to reduce the cognitive difference between users and designers, so as to solve the problem of cognitive asymmetry. This was done firstly by obtaining the review data of products from users on the Internet, based on a web crawler, and then constructing word vectors based on natural language processing techniques to realize the parametric expression of the Kansei image. Secondly, by using a statistical method to extract the product scheme that meets the preferences of users and designers, and then quantifying the relationship between the product form and Kansei image based on a grey relational analysis (GRA). Finally, by calculating the indicator weight based on the Entropy method and using the fuzzy TOPSIS method to explore the prioritization of the product design alternatives in view of the Kansei needs of users. Taking the smart capsule coffee machine as an example, the feasibility and effectiveness of this method are verified. In particular, the method proposed in this research can not only enable different cognitive subjects to achieve cognitive symmetry, but also filter out product forms that meet the cognitive needs of users. Moreover, this study provides a theoretical basis and practical significance for reducing the cognitive differences between cognitive subjects in the whole process of product design, and provides a systematic framework for the industry to effectively connect customer needs and product design decisions. At the same time, this study has introduced a new method for Kansei engineering.

Keywords: natural language processing; grey relational analysis; product evaluation; fuzzy TOPSIS

\section{Introduction}

Due to the increasingly fierce market competition, many companies find that their manufacturing and market research have reached the same level as their competitors, so the only remaining competitive weapon is design innovation and improvement of design quality [1]. Since the form of a product has gotten rid of the shackles for production function in the post-modern era, its lifestyle and emotional value are considered more pivotal in product design [2]. Product design must not only meet the functional requirements of the product, but also pay more attention to the meaning and value created by the product, so as to give consumers functional and psychological expectations [3]. For example, Apple's smartphone research and development often develop a variety of styles of different materials and colors based on different user groups to expand consumer groups for different ages, so as to extend the product life cycle [4]. With the improvement in industrial integration, product differentiation is becoming difficult [5]. Therefore, the user's perception and preference factors must be incorporated into the process of product differentiation production and promotion to assist product design decision-making [6]. The user's emotions and preferences are a customer's psychological response to the product's Kansei design details (such as the shape), and they are also the basis for the formation of human values 
and judgments [7]. In fact, the essence of a product's Kansei design is to design function, which could meet the various expectations and needs of users, so as to make the product emotionally engaging [8]. Therefore, in the product design and development process, it is necessary to consider production design attributes based on the emotional needs of customers, and then to design products with corresponding characteristics to obtain the favor of users $[9,10]$. In order to carry out the Kansei design of products, it is necessary to start with two stages of product concept generation and evaluation. Specifically, the concept generation and evaluation of a product design are two key steps to obtain the optimal design result in the product design stage, where the former could generate possible design concepts and the latter could determine the final selection of candidate design schemes [11]. As a gatekeeper, the impact of design concept evaluation on the novelty, feasibility and quality of the final product is extremely important [12], which is also a big challenge. In order to select the ideal design concept, the design team needs to consider various factors from customer needs, technical attributes and design constraints, and then develop appropriate evaluation models to determine the priority ranking of the candidate design options [11]. Moreover, in order to reduce the impact of the cognitive biases of decision-makers, group decision-making strategies are becoming increasingly common in design concept evaluation [13]. By inviting experts to discuss and determine the evaluation criteria, and give their evaluation information, the ranking of an alternative design plan can be determined.

In fact, Kansei engineering (KE) [14,15] is a theory based on design science, psychology, cognition, and other related disciplines that introduces human perceptual analysis into the field of engineering technology [16]. KE aims to establish a database for consumer perceptions, which can demonstrate the mapping process between Kansei vocabulary and design elements from the perspective of consumers [17]. It is a conversion technology that transforms consumers' feelings and imaginations of products into design elements [18], and generate product solutions and alternative concepts based on the investigation and analysis of visual stimuli [19]. Kansei is a Japanese vocabulary that expresses users' psychological feelings and imaginations of new products [20]. When KE is used, we will pay attention to how people perceive images or objects of a production, as well as study the effect of their personal Kansei preferences or cultural basis on their psychological feelings, then identifying the emotional attributes of customers and associate them with design elements [18].

In essence, the product innovation design scheme is a typical multi-attribute comprehensive decision-making problem (MCDM), which is essentially a multi-objective, multi-level, and uncertain complex decision-making process. Therefore, to explore the way to establish a more precise mapping relationship between user needs and product development has never stopped. In this regard, some MCDM techniques, such as the fuzzy analytic hierarchy process (FAHP) [21], ANN [22], QFD [10], and TOPSIS [23], have been integrated widely with fuzzy sets [24] to effectively be used in making decisions from various solutions. However, these models have certain limitations. Among them, artificial neural networks (ANN) are considered "black box" models, because its performance depends only on the size and quality of the data, and the structural characteristics of the model [7]. In addition, there are two limitations in the application of fuzzy mathematics: (1) The fuzzy mathematics is used to simulate the cognitive process of human beings; however, the determination of the used relational functions is usually based on the experience and intuition of experts. (2) The boundary interval of the fuzzy number is rapidly expanded due to fuzzy arithmetic operations, thus lowering the identifiability of the obtained fuzzy number, and it also deviates from the correct prior result of the customer's needs [25]. Fortunately, grey system theory (GST) is an effective research method [26]. Generally, grey theory provides a technique for transferring information from black (unknown) to white (known), it has the advantage of using uncertain or scattered information to handle complex tasks [27], and its features are suitable for limited sample research [28]. What is more, the GST method takes the grey system of "small sample, little information" as the 
research object [7], so it has superiority in dealing with fuzzy or grey data effectively in the KE.

In addition, in most of the previous KE literature, questionnaire surveys are usually used in the process of obtaining Kansei attributes and product attributes [29]. Doubtless, this traditional method provides high-quality results, but it has some disadvantages, such as a small scale, one-time, and so on. It also has certain limitations in terms of data update and collection efficiency [30]. At the same time, the traditional survey questions are also designed based on expert thinking rather than customer opinions [31], so that the survey results cannot reflect the user's true emotional factors [32]. However, with the development of computer technology and Internet technology, the function of a computer as an information exchange medium has been rapidly expanded. Therefore, online shopping has become a trend to impact consumption patterns [33]. People can choose their favorite products in online shopping and give their own opinions. These data constitute an information network that connects product attributes and user experience, which contains accurate and true user Kansei images information [34]. Thus, this information could help designers to understand consumers' experience and expectations of services and products [35]. Some researchers are interested in using online consumer reviews to gain insights for research issues [31,32,34,36,37]. Although previous text mining studies have explored ways to help customers understand review summaries, few studies can help designers clearly identify customer needs to support the product development process. Therefore, this study uses web crawlers to collect online reviews of products, and utilizes text mining technology to extract the users' real Kansei vocabulary from the reviews, and introduces the users' true evaluation information from the web-crawled big data into the KE, based on constructing an automated method. In this way, the symmetry between the acquired Kansei demands and the real user needs is realized, so as to solve the asymmetry problem in the process of demand acquisition, which has become the focus of this paper. At the same time, this research uses a T-test to quantify the cognitive differences between the designers and users, the extracted products that meet the cognitive needs, and the preferences of the designers and users, as well as to screen out product-form design schemes that show symmetrical affective cognition between users and designers. Finally, an evaluation index is extracted from the high-quality product design schemes and their weights are quantified based on entropy, while the fuzzy TOPSIS method is used to evaluate the product design schemes at the same time, so as to prioritize products according to user needs. Therefore, the innovative design and evaluation of products become more objective based on this proposed method. Moreover, the method proposed in this research provides a quantitative reference for companies and designers to screen out high-satisfaction product design plans. The overall comparison between this article and previous studies is shown in Table 1. Obviously, the main contributions of this article are listed as follows:

1. Excavating the user's Kansei information from network evaluation big data, and to use the natural language processing technology to introduce the user's authentic evaluation information for the Kansei image, which can effectively avoid the deviation between expressed preferences and real emotional appeals in traditional consumer surveys.

2. Extracting products with symmetrical cognitive information between designers and users, and to analyze the contribution degree between the core modeling items and Kansei intentions of the product, so that the selection of key product indicators is completed in a user-centric manner.

3. Making reasonable evaluations based on user needs to determine the priority of alternative product schemes, so as to realize the optimization of multi-attribute decisionmaking for design schemes, and solves the uncertainty and subjective problem of design scheme evaluation in the group decision-making environment, so as to provide better theoretical support for the selection of the best production plan.

In particular, this study attempts to adopt a novel combination method to conduct systematic decision-making research on products from a consumer-centric way, which 
is achieved by a hybrid analytical approach combining natural language processing, $\mathrm{KE}$, GRA, entropy, and fuzzy TOPSIS to achieve effective product innovation program decisionmaking. Firstly, the natural language processing of artificial intelligence is used to qualitatively and quantitatively analyze the Kansei needs of users, and the semantic relationship of each word is accurately communicated in a vector way, and then the results obtained from the Kansei needs of users are further processed for dimensionality reduction based on factor analysis (FA). Then, by using $t$-test and correlation analysis methods to further extract the productions that fit the Kansei between users and designers and determining the contribution degree of the styling project to the Kansei image through GRA, so as to extract the key styling items of the production. On this basis, an entropy and fuzzy TOPSIS model is proposed to further sort the potential products, so that products that meet the user's emotional demand are systematically identified and selected. Therefore, this reasonable product Kansei demand assessment framework provided in this study could realize the optimization of multi-attribute group decision-making of design schemes, and it also provides a better basis for scheme selection. In order to illustrate the effectiveness of the method, the proposed method is verified by using a smart capsule coffee machine as an example.

The rest of this article is structured as follows. Section 2 briefly reviews the concepts of GST and fuzzy TOPSIS. Section 3 introduces the proposed framework. Section 4 verifies the effectiveness of the framework through a case study. The last part summarizes this research and puts forward the problems to be further researched and solved in the future.

Table 1. An overall comparison between this proposed approach and other studies.

\begin{tabular}{|c|c|c|c|c|c|c|}
\hline References & User Need & Kansei Features & Functional Features & $\begin{array}{c}\text { Product } \\
\text { Configuration }\end{array}$ & $\begin{array}{c}\text { Market } \\
\text { Segmentation }\end{array}$ & $\begin{array}{l}\text { Production } \\
\text { Innovation }\end{array}$ \\
\hline This paper & NLP & $\mathrm{KE}$ & Entropy & $\begin{array}{l}\text { GRA, Fuzzy } \\
\text { TOPSIS, FA }\end{array}$ & & \\
\hline $\begin{array}{c}\text { Nagamachi [14] } \\
\text { Nagamachi et al. [38] }\end{array}$ & & $\begin{array}{l}\mathrm{KE} \\
\mathrm{KE}\end{array}$ & & RST & & \\
\hline Ghorbani et al. [39] & & & & $\begin{array}{c}\text { Fuzzy TOPSIS, } \\
\text { FAHP }\end{array}$ & & \\
\hline $\begin{array}{c}\text { Bae and Kim [40] } \\
\text { Wang [41] } \\
\text { Stavrakos et al. [42] }\end{array}$ & Focus group & $\mathrm{KE}$ & RST & $\begin{array}{l}\text { ARM, DT } \\
\text { CA, GRA }\end{array}$ & User preferences & \\
\hline Wang and Wang [43] & rocus group & & Fuzzy Kano, Fuzzy & & Affordable prices & \\
\hline Wang [6] & & $\mathrm{KE}$ & RST & FCRP & & TRIZ \\
\hline Wang and Zhou [44] & Kano & EGM & & $\begin{array}{l}\text { IGA, Evaluation } \\
\text { time }\end{array}$ & & \\
\hline Wang [45] & & & & QFD, CPA & & TRIZ \\
\hline Hsiao et al. [46] & & AHP & & QT-I, GA, & & \\
\hline Wang [7] & & $\mathrm{SD}, \mathrm{KJ}, \mathrm{K}$-means & GRA & SVR, ANN & & \\
\hline Shi et al. [47] & & KE & & RST, ARM & & \\
\hline Lin et al. [48] & & Focus group & Kano & Fuzzy QFD & & \\
\hline
\end{tabular}

QFD: quality function deployment; CA: conjoint analysis; FA: factor analysis; KE: Kansei engineering; EGM: evaluation gird method; NLP: natural language processing; ANN: artificial neural network; RST: rough set theory; ARM: association rule mining; GA: genetic algorithm; SVR: support vector regression; TRIZ: the theory of inventive problem solving; DT: decision tree.

\section{Review}

\subsection{GST}

Grey system theory (GST) was proposed by Professor Deng Julong of Huazhong University of Science and Technology in 1982 [26]. Grey system theory is based on uncertain systems, i.e., where a part of the information is known and a part of the information is unknown, as the research object [49]. In GST, the concept of a grey box is used to describe the characteristics of messages in the actual environment. In grey events, the integrity of the information can be expressed based on the degree of grey. The system is expressed in white when it is completely aware of the information, and the system is expressed in black when it is completely unknown; thus, the system is expressed in grey when it is partially known and partially unknown. The entire grey system can change dynamically with time [1]. For the factors between systems, the correlation size measurement that varies with different objects is called the degree of correlation. The grey correlation analysis method is based 
on the degree of similarity or difference between the development trends of factors in the grey system theory; that is, the "grey correlation degree", which works as a method to quantitatively measure the correlation degree of system changes and development trends for factors [49]. Furthermore, it relies on the mathematical foundation of space theory to determine the geometric similarity between the reference factor sequence and the related factor sequence so as to determine the degree of relevance between the various factors of the system, which is a dynamic analysis process essentially. This method have some features, such as simple calculation, clear sorting, and no special requirements for data distribution types [50]. In essence, the main difference between grey relational analysis (GRA) and traditional mathematics is that grey relational analysis provides a summary framework for analyzing the small analysis amount of used information. Therefore, this method could be widely used in system analysis, management decision-making, and KE [1,28,50-52]. However, in KE, the GRA is only effectively used to analyze the importance of product color and styling items. Doubtless, it lacks the integration of experimental results into the overall aesthetic priority evaluation of the product. Hence, this research explores products that are emotionally compatible with consumers and designers, and uses GRA to analyze the contribution degree of product form elements based on the Kansei demand, and then extracts key modeling features and quantify them as evaluation indicators, which are used as the evaluation carrier of a product's comprehensive satisfaction ranking. In this way, the evaluation result could become more objective and accurate, thus effectively assisting designers in design decision-making.

Therefore, in order to solve the problem of the same item weight in the traditional product design and evaluation process, a method of assigning different item attributes with different weights is proposed, and the key product form items are extracted so as to make the results of the product evaluation more objective and accurate. In this study, the GRA method is adopted to calculate the degree of correlation between the product modeling items and Kansei image, and the priority of modeling elements that affect the product Kansei image is explored precisely so as to guide the design decisions and evaluation during the product development process.

\subsection{The Fuzzy TOPSIS}

Hwang and Yoon (1981) proposed [53] a method of Technique for Order Preference by Similarity to an Ideal Solution (TOPSIS). In fact, its basic idea is based on the shortest distance between the selected solution and the positive ideal solution, and the furthest distance to the negative ideal solution (NIS) so as to select the optimal plan in the decision-making process [54]. Technique for Order Preference by Similarity to Ideal Solution (TOPSIS) has become a mature and effective method in multi-attribute decision-making, which has been widely used in supplier selection research [39], comprehensive ranking of energy supply systems [55], business and market management research [56], product development decision-making and configuration [57]. The application of the TOPSIS method has a straightforward execution process and it is more convenient to use, and its computational requirements are lower than other management decision methods [58]. However, the traditional TOPSIS method can only deal with the situation where the evaluation index value is a quantitative value, and in view of the evaluation of the morphological design plan in the product design stage, there will be evaluation indexes that cannot be quantified. Therefore, it is necessary to introduce fuzzy theory into the TOPSIS method and use the transformation scale to change the language variables converted into triangular fuzzy numbers so as to quantify the qualitative indicators, and then the final scheme ranking is obtained by developing the fuzzy TOPSIS method. At the same time, determining the weight of each criterion of the product design is also an important part of the fuzzy TOPSIS method. By determining the weights of the indicators, all alternatives can be compared based on the overall performance of all criterion. In fact, subjective weighting methods based on the subjective preferences of experts, including AHP, Delphi, FARE, BWM, etc., tend to increase with the number of evaluation indicators, and may lead to the problem that experts may not be able to assign precise weights for each criterion. To this end, this 
problem can be effectively avoided based on the objective weighting method, in which entropy is an effective method, and then the weight value of the evaluation index can be effectively obtained through an analysis of the dispersion of the data.

Accordingly, to review the current KE researches, the fuzzy TOPSIS method is rarely applied in the field of product design and evaluation process. Therefore, in this study, in order to solve the problem whereby the traditional TOPSIS method can only deal with quantitative evaluation indicators, this study tries to use the fuzzy TOPSIS method to evaluate productions to reduce the subjectivity and complexity in the evaluation process of decision makers. At the same time, the entropy method is utilized to obtain the objective weight value of the evaluation item index. Hence, the final ranking of the product sample plans is explored effectively so as to make the evaluation result more accurate and precise.

\section{Method}

In order to meet the needs of users and speed up the product development process, this research proposes a product form design decision-making method driven by user Kansei images based on natural language processing and grey theory. In particular, this method could not only save time in identifying customer needs but also help designers to develop customer-oriented products. Specifically, we first apply the TF-IDF feature extraction method to extract product feature words from user review data, which could make up for the disadvantages of Word2Vec in feature extraction. Meanwhile, we use Word2Vec to map the words to the vector space to obtain the word vector; it also could solve the problem of the inability of the semantic information of words based on the TF-IDF feature extraction method. Hence, this combination method of TF-IDF feature extraction technology and Word2Vec could not only avoid possible over-fitting problems but also fully consider the semantic information of words. Furthermore, we use the SD method, T-test, and correlation analysis method to select the products that are highly compatible with the emotions of users and designers, so that productions with cognitive symmetry are obtained. In order to accurately obtain the key demands of users on product styling items, the expert interview method is used to extract the core key styling features, and grey relational analysis is used to obtain the relationship between styling features and Kansei images, and then the key styling items are screened out. Moreover, through the application of the fuzzy TOPSIS method to the preference analysis of customer demand solutions, the product design solutions that meet the Kansei needs of users are selected, thus guiding the positioning and development of the product conceptual design. As shown in Figure 1, for convenience, the operational procedures include the following steps:

1. Initially, the product feature words are extracted through the natural language process, so as to analyze and mine accurate and real user Kansei image appeals, which could solve the disadvantages in traditional methods of data scale, data credit, data update, and collection efficiency. Consequently, the deviation between the preferences of consumer surveys and real preferences could be effectively reduced, thereby effectively improving the success rate of new product development.

2. Then, in order to determine the difference in the perception of products between designer and customer, the SD method is used to quantify the emotion, and then the T-test method is used to compare the Kansei image scores of all samples from designers and customers, and then choose Pearson correlation analysis to obtain the product samples that meet not just the Kansei needs of users but also the emotional appeals of designers. Hence, such products are a high-quality product form with symmetrical cognitive preferences of users and designers.

3. Thereafter, the grey relational analysis is utilized to quantitatively analyze the relationship between the user's Kansei need and product styling feature factors. According to the experimental results, the contribution of the styling project can be explored, and then the product core styling evaluation project can be selected so as to effectively identify the main design elements that affect the product Kansei image. 
4. Finally, entropy and fuzzy TOPSIS are used to explore the final ranking of the sample plans effectively, to then evaluate and optimize the product form development scheme. Due to the vagueness and uncertainty of emotional information, the fuzzy TOPSIS evaluation method is used to reduce the subjectivity and complexity of the decisionmakers' evaluation for product form schemes, so as to minimize the impact of users' personal subjective factors on the results, and thus making the evaluation results more precise.

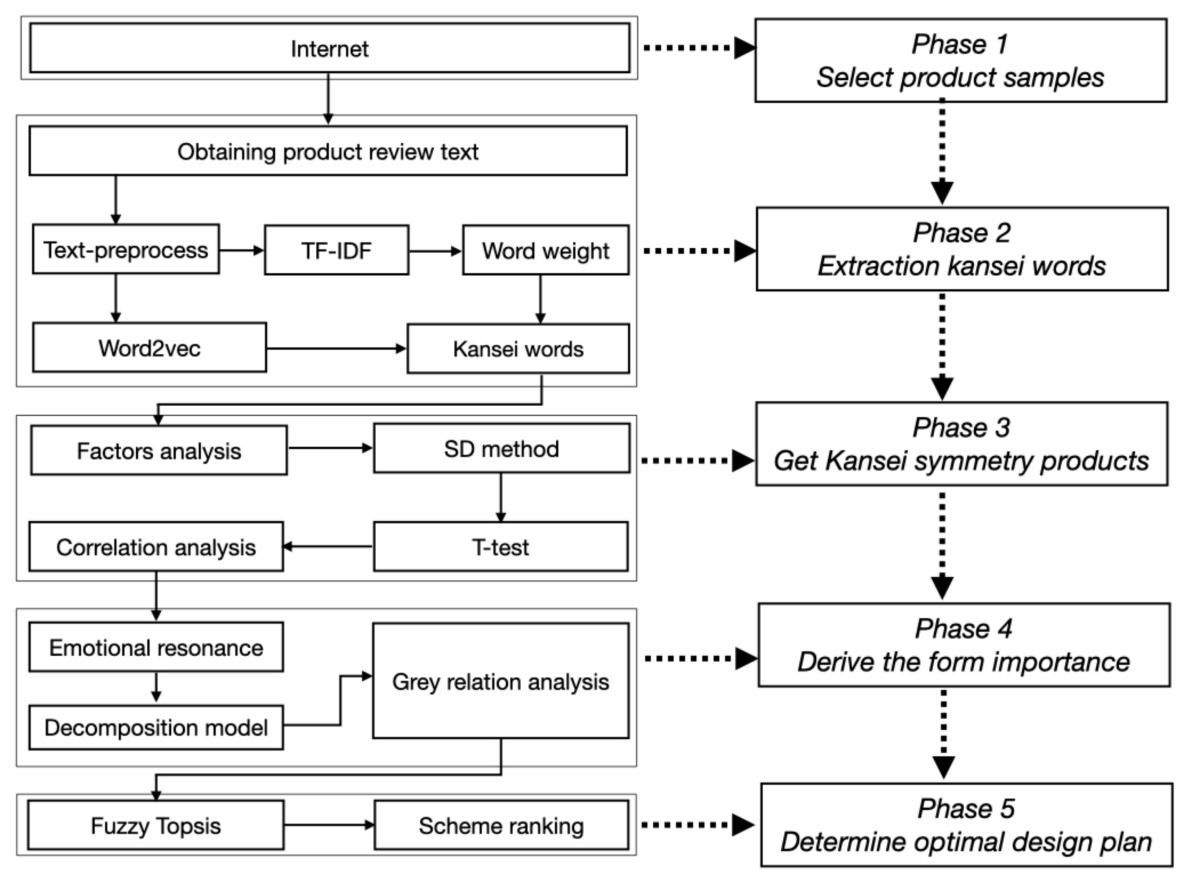

Figure 1. The general framework for production design in this study.

\subsection{Natural Language Processing}

The main task of product review mining is the extraction of product feature words and the emotional evaluation of product feature words [59]. It mainly refers to the use of natural language processing [60], computational linguistics, statistics analysis, and other technologies that automatically identify and extract useful information from texts [61], which is essentially a process of using natural language processing and machine learning techniques to obtain high-quality information from unstructured texts [31,62]. How to represent words in a form that can be processed by machines is the basis of natural language processing. The most intuitive way of representing word vectors is one-hot representation, but this high-dimensional and sparse representation is very easy to fall into the "curse of dimensionality". This method makes the machine unable to judge the degree of relevance between word vectors, nor can it store the semantic information of words. Fortunately, Hinton (Hinton, 1986) proposed Distributed Representations to represent semantics to perfectly solve the above problems. Among them, Word2Vec, as a more prominent method, was first developed by Google's Tomas Mikolov et al. [63]. It was proposed in 2013 by using the middle layer parameters of the model to convert natural language vocabulary from the one-hot form into a word vector model represented by a fixed-length dense vector. The semantic logical relationship between words can be reflected by the correlation between word vectors. Essentially, this model is a word prediction model based on the core algorithm of a neural network (Figure 2). Its training samples are words in the text (target words) and words in their context, and the target words are predicted by the context words of the target words. At the same time, in order to quickly create a vector space in Word2Vec, it can be easily composed of hundreds of dimensions [63]. This semantic vector space reflects the hypothesis of distributed semantics, that is, words that appear in the same context often has a similar meaning [64]. Two methods are most commonly 
used when building Word2Vec models, namely, continuous bag-of-words (CBOW) and skip-gram (Figure 3). In the CBOW method, surrounding words are used to predict the current word [64], while skip-gram tries to predict words in a window of size $c$ from the current word. In fact, skip-gram models tend to perform better on smaller data sets [64]. Therefore, this study could use a skip-gram model for research.

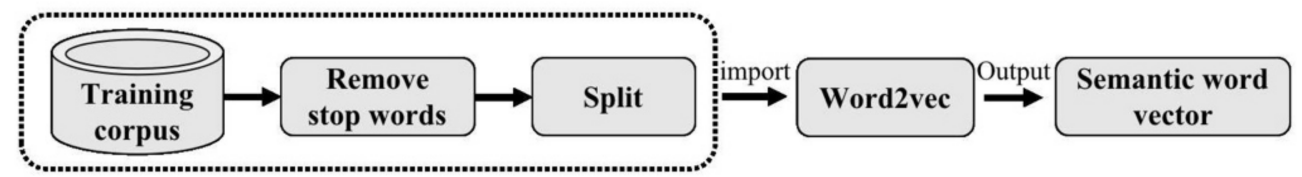

Figure 2. Corpus preprocessing and Word2Vec.

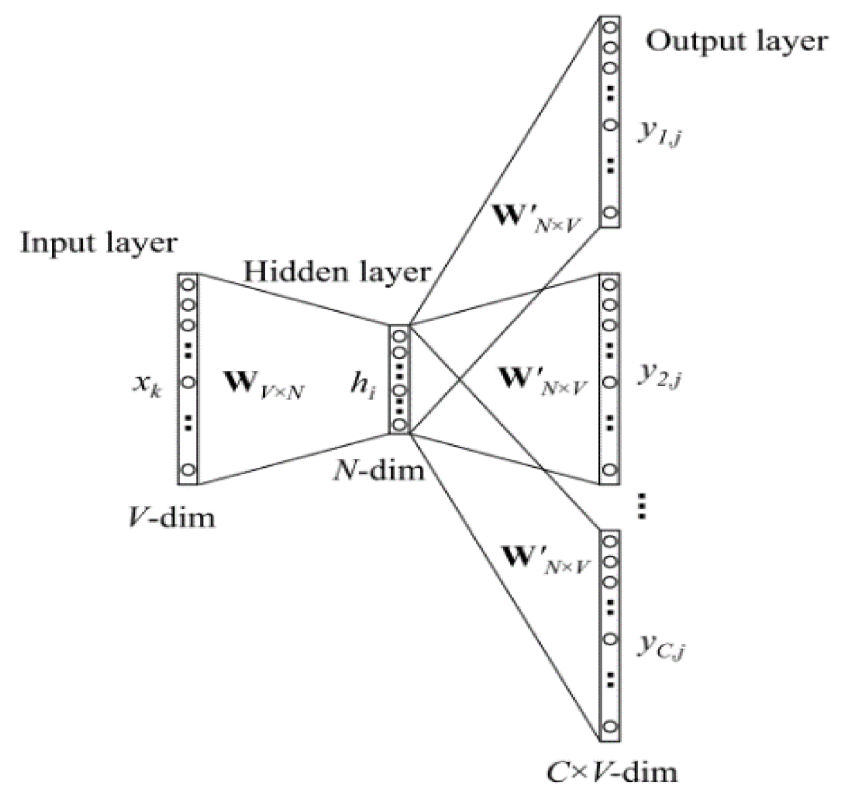

Figure 3. The skip-gram model [65].

This study uses the way of web crawlers to further filter the data on the Internet, and then uses the Jieba word segmentation tool for further research, finally drawing the word cloud and calculating the importance of each word through TF-IDF. Term frequencyinverse document frequency (TF-IDF) [66] is a commonly used weighting technique for information retrieval and text mining to quantify the strength of each Kansei vocabulary. The importance of each word increases in proportion to the number of times it appears in the document. However, at the same time, it will decrease in inverse proportion to the frequency of its appearance in the corpus. The specific steps are as follows:

For a set $D$ containing $M$ Chinese texts, first use the Jieba tool to segment each text in the set $D$ and remove the stop words, and then use the TF-IDF algorithm to calculate its weight in the text TF-IDF $F_{i, j}$, which could represent the weight of the word $t_{i}$ in the text $D_{j}(j=1,2,3, \ldots, M)$, calculated by Equation $(1)$ :

$$
T F-I D F_{i, j}=T F_{i, j} \times I D F_{i}
$$

In Equation (2): $n_{i, j}$ is the number of occurrences of the word $t_{i}$ in the text $D_{j}$, and the denominator is the sum of the number of occurrences of all words in the text $D_{j}$ :

$$
T F_{i, j}=\frac{n_{i, j}}{\sum_{k} n_{k, j}}
$$

In Equation (3), $|D|$ is the total number of texts in the corpus, $|\{j: t i \in D j\}|$ contains the number of texts of the word $t_{i}$, which is the number of texts with $n_{i, j} \neq 0$; if the word is 
not in the corpus, it will result in a zero denominator. Therefore, in general, $1+|\{j: t i \in D j\}|$ is used. The high word frequency in the particular text and the low text frequency of the word in the entire text collection can produce a high weight for TF-IDF. Therefore, TF-IDF tends to filter common words and retain important words.

$$
I D F_{i}=\lg \frac{|D|}{\left|\left\{j: t_{i} \in D_{j}\right\}\right|}
$$

Since TF-IDF can only extract high-weight Kansei words, it cannot consider the semantic information of the words in the overall semantic context. The word vector converted by the Skip_gram model of Word2Vec can retain the main semantic information and the neural network takes a word $w_{t}$ as input and tries to predict the words $w_{t+i}$ around it. Through input-output one selects a random index value $i$ from the skip-gram program window $c$ to randomly sample $k$ times, and all the sample values of $i$ of an input word $w_{t}$ come from the set $J$. Therefore, the training goal is defined as Equation (4) [64], and finally the Kansei vocabulary of the word vector that retains the semantic information of the word is obtained.

$$
\frac{1}{\mathrm{~T}_{i}} \sum_{t=1}^{T} \sum_{\forall i \in J} \log p\left(w_{t+i} \mid w_{t}\right)
$$

\subsection{Grey Relational Analysis}

Grey theory provides a metric called the "Grey Correlation Coefficient" to measure the closeness of the comparison alternatives and benchmark alternatives (reference series). For convenience, we have adopted a five-level scoring standard, and the details are as follows [41]:

To establish a comparison series: assume that $X$ represents an $m \times n$ matrix to collect the evaluation of the performance level of $n$ dimension elements in $m$ alternatives, where $x_{i}(k)$ represents the element $k$ of alternative $i, m$ is the number of series (alternatives), and $n$ denotes the number of criteria (attributes).

$$
\mathrm{X}=\left[\begin{array}{cccc}
x_{1}(1) & x_{1}(2) & \cdots & x_{1}(n) \\
x_{2}(1) & x_{2}(2) & \cdots & x_{2}(n) \\
\vdots & & & \vdots \\
x_{m}(1) & x_{m}(2) & \cdots & x_{m}(n)
\end{array}\right]
$$

Setting the reference series: the elements of the reference series are set by their corresponding maximum rating scales (similar to an ideal solution).

$$
x_{r}=\left\{\left(\max x_{i}(j)\left|j i_{i} \in \hat{J}\right|,\left(\min x_{i}(j) \mid j \underset{i}{j} \hat{J}\right) \mid i=1,2, \ldots, m\right\}\right.
$$

where $J$ denotes the set of benefit (the-larger-the-better) terms and $J$ denotes the set of cost (the-smaller-the-better) terms.

Computing 'the degree of greyness' between the target series and the reference series via the following deviation matrix:

$$
\Delta=\left[\begin{array}{cccc}
\Delta_{1 r}(1) & \Delta_{1 r}(2) & \cdots & \Delta_{1 r}(n) \\
\Delta_{2 r}(1) & \Delta_{2 r}(2) & \cdots & \Delta_{2 r}(n) \\
\vdots & & & \vdots \\
\Delta_{m r}(1) & \Delta_{m r}(2) & \cdots & \Delta_{m r}(n)
\end{array}\right]
$$

where $\Delta_{i r}(j)=\left\|x_{i}(j)-x_{r}(j)\right\|, x_{i}(j)$, and $x_{r}(j)$ represent the $j$ th element of the target and the reference series, respectively. 
The attribute-based grey correlation coefficient is calculated as follows:

$$
\begin{gathered}
\gamma\left(x_{i}(j), x_{r}(j)\right)=\frac{\Delta_{\min }+\xi \Delta_{\max }}{\Delta_{i r}(j)+\xi \Delta_{\max }} \\
\Delta_{\min }=\min _{\forall i} \min _{\forall j}\left\|x_{i}(j)-x_{r}(j)\right\| \\
\Delta_{\max }=\max _{\forall i} \max _{\forall j}\left\|x_{i}(j)-x_{r}(j)\right\|
\end{gathered}
$$

where a distinguishing coefficient $\xi \in(0,1)$ is generally set at the value of 0.5 .

Averaging the degree of grey relation to prioritize the product varieties:

$$
\Gamma\left(x_{i}(j), x_{r}(j)\right)=\frac{1}{n} \sum_{j=1}^{n} \gamma\left(x_{i}(j), x_{r}(j)\right)
$$

\subsection{The Fuzzy TOPSIS}

The concept of Fuzzy TOPSIS is to find a positive ideal solution (PIS) and a negative ideal solution (NIS) as the comparison criteria for each choice. By comparing the Euclidean distance between the ideal solution and the alternatives, the closeness of the alternatives is obtained, and then the pros and cons of the alternatives are ranked. Furthermore, firstly, calculate the fuzzy rating of the standardized assembly of the target image and the brandnew sample. If the fuzzy rating of the $k$-th decision maker is $\widetilde{x}_{i j k}=\left(a_{i j k}, b_{i j k}, C_{i j k}\right)$, the aggregate fuzzy rating of each new sample is as follows [67]:

$$
\tilde{x}_{i j}=\left(a_{i j}, b_{i j}, C_{i j}\right) ;
$$

where

$$
a_{i j}=\min \left\{a_{i j k}\right\} ; b_{i j}=\frac{1}{k} \sum_{k=1}^{k} b_{i j k} ; C_{i j}=\max \left\{C_{i j k}\right\}
$$

Therefore, the standardized fuzzy decision matrix can be expressed as

$$
\begin{gathered}
\widetilde{R}=\left[\widetilde{r}_{i j}\right]_{m \times n} \\
\widetilde{r}_{i j}=\left(\frac{a_{i j}}{c_{j}{ }^{+}}, \frac{b_{i j}}{c_{j}{ }^{+}}, \frac{c_{i j}}{c_{j}{ }^{+}}\right), j \in B \\
\widetilde{r}_{i j}=\left(\frac{a_{j}^{-}}{c_{i j}}, \frac{a_{j}^{-}}{b_{i j}}, \frac{a_{j}^{-}}{a_{i j}}\right), j \in C \\
c_{j}^{+}=\max \left(c_{i j}\right), j \in B \\
c_{j}^{+}=\max \left(c_{i j}\right), j \in C
\end{gathered}
$$

where $B$ and $C$ are the set of benefit criteria and the set of cost criteria, respectively.

Taking into account the different importance of the criteria, the weighted normalized fuzzy decision matrix is constructed as

$$
\begin{gathered}
\widetilde{V}=\left[\widetilde{v}_{i j}\right]_{m \times n^{\prime}}, i=1,2, \cdots, m, \mathrm{j}=1,2, \cdots, \mathrm{n} ; \\
\widetilde{v}_{i j}=\widetilde{r}_{i j}(\cdot) \widetilde{w}_{j}
\end{gathered}
$$

The fuzzy optimal ideal solution $A^{+}$and the fuzzy worst ideal solution $A^{-}$can be defined as, respectively,

$$
\begin{aligned}
& A^{+}=\left(\widetilde{\mathrm{v}}_{1}^{+}, \widetilde{\mathrm{v}}_{2}^{+}, \ldots, \widetilde{\mathrm{v}}_{n}^{+}\right), \widetilde{\mathrm{v}}_{j}^{+}=\max \left\{v_{i j 3}\right\} \\
& A^{-}=\left(\widetilde{\mathrm{v}}_{1}^{-}, \widetilde{\mathrm{v}}_{2}^{-}, \ldots, \widetilde{\mathrm{v}}_{n}^{-}\right), \widetilde{\mathrm{v}}_{j}^{-}=\min \left\{v_{i j 1}\right\}
\end{aligned}
$$


For each new sample, the distance between the candidate solution and the optimal solution $A^{+}$and the worst solution $A^{-}$is defined as

$$
\begin{aligned}
& d_{i}^{\dot{+}}=\sum_{j=1}^{n} d_{v}\left(\widetilde{v}_{i j}, \widetilde{v}_{j}^{\dot{+}}\right), i=1,2, \ldots, m \\
& d_{i}^{-}=\sum_{j=1}^{n} d_{v}\left(\widetilde{v}_{i j}, \widetilde{v}_{j}^{-}\right), i=1,2, \ldots, m
\end{aligned}
$$

where

$$
d_{v}(\widetilde{m}, \widetilde{n})=\sqrt{\frac{1}{3} \sum_{i=1}^{3}\left(m_{i}-n_{i}\right)^{2}}
$$

Then, the relative closeness of each new sample to the ideal solution is calculated, as the final criterion to determine the sort order of all alternatives.

$$
\mathrm{CC}_{i}=\frac{d_{i}^{-}}{d_{i}^{\dot{+}} \dot{+} d_{i}^{-}}, i=1,2, \ldots, m .
$$

Finally, the new samples are arranged according to the descending order of closeness, and the new sample that ranked first is the best solution, which is the closest to the optimal solution and the farthest to the worst solution.

\subsection{Information Entropy}

Entropy refers to the degree of chaos in the system, which is the measure of the possibility (probability) of the system in a certain macroscopic state. Entropy is derived from information theory and it has become a powerful indicator to measure the content factors of uncertain information [57]. Assuming that the uncertainty of the information is represented by a discrete probability distribution composed of $k$ categories $\left(p_{1}, p_{2}, \ldots, p_{\mathrm{k}}\right)$, the distribution containing larger variables in all $p_{i}{ }^{\prime}$ s has more uncertainty than the distribution of smaller variables. Specifically, information entropy is defined as [57]

$$
E\left(p_{1}, p_{2}, \cdots, p_{k}\right)=-\varnothing_{k} \sum_{i=1}^{k} p_{i} \text { In } p_{i}
$$

where $\varnothing_{k}=1 / \ln (k)$ is a positive constant to ensure that the entropy will be limited to the interval $[0,1]$.

Then, the weight $w_{j}$ of the target attribute in the product evaluation process can be derived as

$$
w_{j}=\frac{1-E\left(x_{j}\right)}{\sum_{j}\left(1-E\left(x_{j}\right)\right)},
$$

where $E\left(x_{j}\right)$ represents the entropy of attribute $j$.

\section{Case Study}

\subsection{Construction of the Semantic Space of Product Modeling}

In this section, we describe a smart capsule coffee machine as the research object. The product shape design of the smart capsule coffee machine is more complicated, and many features interact with each other to convey the unique Kansei image to users. Therefore, this study selected the shape of the smart capsule as the design object to verify the feasibility of the method. Firstly, the popular smart capsule coffee machine products sold on the internet could be collected to capture the product Kansei semantic image space. Customer reviews are collected from the two most popular mainstream e-commerce websites (Taobao, JingDong). Then, we searched for the smart capsule coffee machine that users prefer based on the most recent year's sales and the number of reviews as a test sample. A total of 10 smart capsule coffee machine products were selected from two platforms, and then 
20 smart capsule coffee machine productions were used as the specific products of this case study, and the review page of each website selling a specific capsule coffee machine was used as the text data for analysis. In the review page, this study used the web crawler tool Jieba to capture the text content of the reviews, excluding the user's name, date, rating, and project pictures, so that the results of the text mining only reflect the customer's Kansei image. To ensure that the selected products are sought after by consumers, the minimum comment crawling page for each sample on the Taobao platform was set to 10 pages, and the minimum comment crawling page for each sample on the Jingdong platform was set to 15 pages. The total number of comments was composed of 127,765 words, and the total user reviews obtained were exported to a .TXT file for subsequent text mining analysis. Then, by using the Jieba tool in Python software to obtain the user review information, the irrelevant stop words were removed, and then performing word segmentation on the text, creating the word cloud of the segmented text. Accordingly, it was found that most users pay more attention to the smart capsule coffee machine products from a comprehensive perspective, such as the appearance, style, and quality of the smart capsule coffee machine. Moreover, to extract the feature words from the word segmentation results based on the Equation (1), the keywords and weights of these 20 examples of user online comments could be obtained, selecting the top 100 user evaluation keywords according to the rule of the weight values in descending order. Part of the results is described in Table 2.

Table 2. Product keywords and weights.

\begin{tabular}{ccccccccc}
\hline Rank & $\mathbf{1}$ & $\mathbf{2}$ & $\mathbf{3}$ & $\mathbf{4}$ & $\mathbf{5}$ & $\mathbf{6}$ & $\mathbf{7}$ & $\mathbf{8}$ \\
\hline Words & Coffee & Coffee & Capsule & Good & Attractiveness & taste & Like & cup \\
W & 0.304 & 0.260 & 0.257 & 0.110 & 0.087 & 0.085 & 0.085 & 0.075 \\
Rank & 9 & 10 & 11 & 12 & 13 & 14 & 15 & 16 \\
Words & Operation & Machine & Compact & delicious & Starbuck & Simple & Taste & Clean \\
W & 0.067 & 0.066 & 0.063 & 0.058 & 0.058 & 0.053 & 0.052 & 0.050 \\
$\vdots$ & $\vdots$ & $\vdots$ & $\vdots$ & $\vdots$ & $\vdots$ & $\vdots$ & $\vdots$ & $\vdots$ \\
Rank & 85 & 86 & 87 & 88 & 89 & 90 & 91 & 92 \\
Words & Penguin & Sound & Fragrant & Unique & Evaluation & Convenient & Production & Activity \\
W & 0.016 & 0.015 & 0.015 & 0.015 & 0.015 & 0.015 & 0.015 & 0.015 \\
Rank & 93 & 94 & 95 & 96 & 97 & 98 & 99 & 100 \\
Words & Office & Poor & Father & Gift & Coffee shop & Form & Pleasure & Functional \\
W & 0.015 & 0.014 & 0.014 & 0.014 & 0.013 & 0.013 & 0.013 & 0.013 \\
\hline
\end{tabular}

According to Table 2, it can be found that 100 user evaluation keywords include some adjectives related to the user's emotional feelings after experiencing a product, as well as some product-related use words, such as operation, Starbucks, coffee shop, cleaning, sound, milk froth, taste, making, and so on. In order to select the words that reflect the users' inner feelings about the product shape from 100 user evaluation keywords, and further extracting the users' emotional experience of the Kansei words from these 100 keywords-to capture the users' inner emotional feelings about the product form-so as to extract 18 Kansei words, it was needed to mine the users' real perceptual demand information from the network review big data. However, only capturing the users' perceptual appeal to the product is often limited. In view of the product form design, activity begins with the designer's ideographic communication, and finally depend on the user's feelings and understanding, the core of which lies in expression and communication. Some studies mainly involve tactile comparisons of textile materials [68], wine aroma [69], pearl quality [70], the aesthetic characteristics of artistic works [71], etc., especially in sensory evaluation [72-74], these studies have demonstrated that emotion perception and evaluation vocabulary vary with the difference in professional level. In fact, the demands of the designer have been built into the product design, which is different from the meaning of the product in the eyes of the user. This contradiction will lead to the failure of the product design. To this end, it 
is necessary to investigate the demands of experts and designers on the product in order to improve the dimension of the Kansei mining. Specifically, interviews between experts and designers were used to investigate the semantic space of related perceptual images corresponding to the samples, and 20 smart capsule coffee machine product samples were processed in A4 size, and the resolution was set to a uniform $100 \mathrm{dpi}$, and the background was removed to make the samples clear. At the beginning of the experiment, a group of eight product designers with extensive experience participated in the survey of the product perceptual image factors, including four males and four females. The age of the participants was 21-40 years old. At the same time, the subjects were asked to perform a perceptual evaluation and description of the product samples, extract the designer's perceptual semantic space vocabulary for the product based on the results, and use the $\mathrm{KJ}$ simplification method to further merge the results of the investigation, and finally obtain seven Kansei image vocabularies. These seven vocabularies also appear in the web crawler corpus of the smart capsule coffee machine product but are not in the top 100 vocabularies. Then the obtained designer Kansei vocabulary was merged with the user Kansei vocabulary crawled by the network information. Finally, 25 composite Kansei image semantic vocabulary of the smart capsule coffee machine products were obtained (see Table 3).

Table 3. Filter Kansei vocabulary.

\begin{tabular}{cccccc}
\hline Type & \multicolumn{5}{c}{ Kansei Words } \\
\hline \multirow{4}{*}{ Users } & Charm & Perfect & Quality & Beautiful & Simple \\
& Dexterous & Satisfied & Functional & Exquisite & Special \\
& Delicate & Useful & Upright & Practical & Suitable \\
& Cute & Fashionable & Designed & $/$ & $/$ \\
\hline \multirow{2}{*}{ Designers } & Convenient & Stylish & Soft & Plump & Technology \\
& Creative & Personality & $/$ & $/$ & $/$ \\
\hline
\end{tabular}

\subsection{Extraction of Key Semantic Features}

According to Table 3, if we directly investigate the cognition of users and experts on these 25 Kansei images' adjectives, the cognitive load between the experts and users will increase. Additionally, these 25 groups of Kansei vocabulary could also partially overlap in the dimension of the word meaning, describing the product style as a 25-dimension vector that will also increase the difficulty of data computation, which is not conducive to obtain effective experimental results. To this end, it is necessary to reduce the dimensionality of the product styling image and dig out the key semantic adjectives that affect the smart capsule coffee machine. Firstly, in view of context of the overall semantics, word vectors were constructed based on the Word2Vec, and then these 25 semantic words were converted into word vectors, so as to accurately express the meaning of the words. Specifically, using Word2Vec to set the crawled user online review data as the original data, the word vector dimension was set as 200, further training the text word vector to realize the parameterized expression of the Kansei words, and then revealing the semantic features of the vocabulary connotation (see Table 4). 
Table 4. Word vector output.

\begin{tabular}{cccccccccc}
\hline Kansei Words & $\mathbf{1}$ & $\mathbf{2}$ & $\mathbf{3}$ & $\mathbf{4}$ & $\ldots$ & $\mathbf{1 9 7}$ & $\mathbf{1 9 8}$ & $\mathbf{1 9 9}$ & $\mathbf{2 0 0}$ \\
\hline Charm & -0.177 & 0.191 & -0.087 & 0.064 & & 0.089 & -0.054 & -0.001 & -0.036 \\
Perfect & -0.049 & 0.135 & -0.103 & 0.005 & $\ldots$ & -0.099 & -0.062 & 0.006 & 0.021 \\
Quality & -0.092 & -0.130 & -0.072 & -0.152 & $\ldots$ & 0.085 & -0.142 & 0.113 & -0.032 \\
Beautiful & -0.037 & 0.077 & -0.223 & 0.110 & $\ldots$ & -0.131 & -0.122 & -0.054 & 0.087 \\
Simple & -0.082 & 0.111 & -0.161 & 0.136 & $\ldots$ & -0.078 & -0.274 & -0.025 & 0.017 \\
Dexterous & 0.021 & 0.097 & -0.163 & 0.003 & $\ldots$ & -0.069 & -0.293 & 0.050 & 0.130 \\
Satisfied & -0.148 & 0.054 & -0.160 & 0.020 & $\ldots$ & 0.035 & 0.049 & 0.024 & -0.076 \\
Useful & -0.107 & 0.106 & -0.251 & 0.171 & $\ldots$ & -0.044 & -0.138 & -0.001 & -0.063 \\
Exquisite & -0.127 & 0.119 & -0.171 & -0.020 & $\ldots$ & -0.081 & -0.211 & 0.063 & 0.030 \\
: & $\vdots$ & & $\vdots$ & $\vdots$ & $\vdots$ & $\vdots$ & $\vdots$ & $\vdots$ & $\vdots$ \\
Fashionable & -0.039 & 0.137 & -0.155 & 0.089 & $\ldots$ & -0.072 & -0.179 & -0.086 & 0.025 \\
Designed & -0.049 & 0.120 & -0.086 & 0.046 & $\ldots$ & -0.113 & -0.105 & -0.033 & 0.091 \\
Personality & -0.029 & 0.070 & -0.036 & 0.042 & $\ldots$ & -0.024 & -0.012 & -0.040 & 0.047 \\
Convenient & -0.022 & 0.132 & -0.137 & 0.091 & $\ldots$ & -0.101 & -0.157 & -0.017 & 0.041 \\
Stylish & -0.035 & 0.069 & -0.074 & 0.049 & $\ldots$ & -0.057 & -0.013 & -0.026 & 0.054 \\
Soft & -0.057 & 0.063 & -0.049 & 0.036 & $\ldots$ & -0.047 & 0.040 & -0.017 & 0.086 \\
Plump & -0.057 & 0.081 & -0.033 & 0.061 & $\ldots$ & 0.006 & 0.026 & -0.018 & 0.018 \\
Technology & -0.111 & 0.088 & -0.077 & 0.051 & $\ldots$ & -0.077 & 0.072 & -0.029 & 0.095 \\
\hline
\end{tabular}

Furthermore, performing a dimensionality reduction operation on the obtained Kansei semantic matrix, the purpose is to condense 25 image semantic words without the loss of interpretation ability. Firstly, based on the KMO sampling appropriateness test and the Barlett spherical test, to determine whether the Kansei semantics is suitable for factor analysis, the $\mathrm{KMO}=0.866$, Barlett's Test value $\mathrm{s}=9220.807$, degrees of freedom $=253$, and significance $=0.000$. According to the research results, the value of $\mathrm{KMO}$ is greater than 0.5 , which means that the result is reasonable. The significance factor is 0.000 , which is less than 0.05 , so there is an obvious difference (see Table 5). Therefore, according to experimental results, the data can be further analyzed based on the factor analysis.

Table 5. The KMO and Bartlett's test.

\begin{tabular}{lcc}
\hline \multicolumn{2}{c}{ Kaiser-Meyer-Olkin Measure of Sampling Adequacy } & $\mathbf{0 . 8 6 6}$ \\
\hline \multirow{3}{*}{ Bartlett's Test of Sphericity } & Approx. Chi-Square & 9220.807 \\
\cline { 2 - 3 } & Df & 253 \\
\cline { 2 - 3 } & Sig & 0.000 \\
\hline
\end{tabular}

The principal component analysis method in the factor analysis was used to extract the common factors. The selection rule was that the characteristic value is greater than 1. As a result, a total of three main factors were selected, and the maximum variance axis method (varimax) can make the representative meaning of each factor more obvious and easier to explain. The maximum variance method in the principal component analysis method was then used to orthogonally rotate each factor, to obtain the rotating component matrix table (see Table 6). In this study, the extraction criterion is that the initial feature value is greater than 1 , and then three factors were extracted (see Table 6), which could explain $82.706 \%$ of all the factor variables. This could mean that these three factors can describe the modeling style characteristics of the experimental sample cases well. The load of the first factor is between 0.858 and 0.611 , which is named as refined and concise. The load of the second factor is between 0.875 and 0.676 , which is named as personalized and fashionable. Moreover, the load of the third factor is between 0.699 and 0.324 , which is named as dynamic and flexible. 
Table 6. Rotated component matrix.

\begin{tabular}{|c|c|c|c|}
\hline \multirow{2}{*}{ Kansei Words } & \multicolumn{3}{|c|}{ Factor } \\
\hline & 1 & 2 & 3 \\
\hline Beautiful & 0.858 & 0.229 & 0.286 \\
\hline Simple & 0.699 & 0.340 & 0.494 \\
\hline Dexterous & 0.815 & 0.341 & 0.271 \\
\hline Exquisite & 0.852 & 0.331 & 0.247 \\
\hline Delicate & 0.799 & 0.293 & 0.281 \\
\hline Useful & 0.729 & 0.407 & 0.442 \\
\hline Upright & 0.708 & 0.348 & 0.562 \\
\hline Practical & 0.611 & 0.455 & 0.590 \\
\hline Cute & 0.759 & 0.436 & 0.115 \\
\hline Fashionable & 0.841 & 0.326 & 0.286 \\
\hline Designed & 0.849 & 0.407 & 0.204 \\
\hline Convenient & 0.676 & 0.469 & 0.415 \\
\hline Stylish & 0.580 & 0.750 & 0.212 \\
\hline Soft & 0.436 & 0.834 & 0.144 \\
\hline Plump & 0.200 & 0.875 & 0.367 \\
\hline Technology & 0.568 & 0.754 & 0.067 \\
\hline Suitable & 0.426 & 0.676 & 0.300 \\
\hline Personalized & 0.516 & 0.811 & 0.155 \\
\hline Quality & 0.442 & 0.370 & 0.561 \\
\hline Creative & -0.001 & -0.212 & 0.324 \\
\hline Satisfied & 0.441 & 0.424 & 0.682 \\
\hline Functional & 0.415 & 0.461 & 0.699 \\
\hline Special & 0.333 & 0.406 & 0.625 \\
\hline $\begin{array}{l}\text { Percentage of } \\
\text { variance }\end{array}$ & 72.089 & 5.882 & 4.735 \\
\hline $\begin{array}{l}\text { Cumulative } \\
\text { percentage }\end{array}$ & 72.089 & 77.972 & 82.706 \\
\hline Kansei word & $\begin{array}{l}\text { Refined and } \\
\text { concise }\end{array}$ & $\begin{array}{l}\text { Personalized and } \\
\text { fashionable }\end{array}$ & Dynamic and flexible \\
\hline
\end{tabular}

\subsection{Comparison of Cognitive Preferences between Designers and Users}

Taking the three groups of Kansei words-concise and simple, personalized and fashionable, and dynamic and flexible - as the evaluation carrier, the designer and user's perception of the product was quantified through experimental investigation, and then the consumer and designer's perception emotional preference of the smart capsule coffee machine was analyzed. Firstly, through the semantic difference method (SD), 30 designers and 30 users were investigated for the quantified values of the Kansei vocabulary of 20 samples for these three semantic spaces, and the pros and cons of the semantic adjectives were divided by a 7-level Likert scale (see Table 7). For the two groups of people participating in the experiment (designers and users), the results of the experiment were calculated using the statistical method of sample averaging. Based on the experimental results, the next step was to use the T-test method to explore whether there are statistically obvious differences between the designer and the customer based on the average value of the Kansei image for each product. Taking the exquisite and concise Kansei image as an example, an independent sample T-test was performed, and the experimental results obtained are shown in Table 8. According to Table 8, it can be seen that $p=0.001<0.05$. Therefore, the $95 \%$ confidence level between the designer and the customer have obvious differences on the exquisite and simple Kansei images of the product. According to the experimental results, there is an obvious difference between the designer and the customer at the $95 \%$ confidence level in the dynamic and flexible $(p=0.033)$ Kansei image, while the personalized and fashionable $(p=0.06)$ Kansei image have no significant difference at the $95 \%$ confidence level. 
Table 7. Example of the questionnaire implemented in the Kansei evaluation.

\begin{tabular}{ccccccccc}
\hline & & & & & & & & \\
\hline $\begin{array}{c}\text { Corsonalized and } \\
\text { fashionable }\end{array}$ & 3 & 2 & 1 & 0 & -1 & -2 & -3 & $\begin{array}{c}\text { Conventional and } \\
\text { traditional }\end{array}$ \\
\hline $\begin{array}{c}\text { Dynamic and flexible } \\
\text { Refined and concise }\end{array}$ & 3 & 2 & 1 & 0 & -1 & -2 & -3 & Stiff and stable \\
\hline
\end{tabular}

Table 8. The experimental result based on an independent sample T-test.

\begin{tabular}{|c|c|c|c|c|c|c|c|}
\hline \multirow{2}{*}{\multicolumn{2}{|c|}{ Kansei Images }} & \multirow{2}{*}{$\mathbf{F}$} & \multirow{2}{*}{ Significance } & \multirow{2}{*}{$\begin{array}{l}\text { Degrees of } \\
\text { Freedom }\end{array}$} & \multirow{2}{*}{$\begin{array}{c}\text { Sig. } \\
\text { (Two-Tailed) }\end{array}$} & \multicolumn{2}{|c|}{ 95\% Confidence Interval } \\
\hline & & & & & & Lower Limit & Upper Limit \\
\hline \multirow{2}{*}{$\begin{array}{l}\text { Refined and } \\
\text { concise }\end{array}$} & $\begin{array}{l}\text { Assumed equal } \\
\text { variance }\end{array}$ & 10.821 & 0.002 & 36 & 0.001 & -1.23975 & -0.35636 \\
\hline & $\begin{array}{c}\text { Not assumed equal } \\
\text { variance }\end{array}$ & & & 22.763 & 0.001 & -1.24884 & -0.34727 \\
\hline
\end{tabular}

\subsection{Designer and User Emotion Matching Analysis}

In order to study the related factors between the emotional response of the electric bicycle product perceived by the designers and customers, a correlation analysis was carried out. If the consumer feeling stimulated by the smart capsule coffee machine product is consistent with the emotional feeling of the designer to promote the product, the design could be considered to have a high matching quality, which can effectively reduce the cognitive difference between the designers and users. Firstly, five design experts with rich design experience for more than 5 years were recruited to form a designer group, who then classified the products of the smart capsule coffee machines promoted in the market. According to their suggestions, these 20 products were finally grouped into five categories. The five categories also cover the most popular and typical smart capsule coffee machines on the market (see Table 9).

Table 9. Typical electric bicycle categories.

\begin{tabular}{ccc}
\hline Number of Categories & Category Style & Description \\
\hline 1 & $\mathrm{C}_{1}$ & Bionic type \\
\hline 2 & $\mathrm{C}_{2}$ & Business type \\
\hline 3 & $\mathrm{C}_{3}$ & Office type \\
\hline 4 & $\mathrm{C}_{4}$ & Cartoon type \\
\hline 5 & $\mathrm{C}_{5}$ & Dexterous type \\
\hline
\end{tabular}

Based on these five product modeling categories, a semantic difference method experiment was carried out to quantify the experts' semantic preference for his/her Kansei vocabulary, and the corresponding perceptual value was obtained. Then, in order to quantify the quality of the emotional matching between the designers and users, a correlation analysis was carried out on the two sets of quantitative data surveyed on the users and experts. Firstly, the expert's category image score was put into SPSS as the target standard, and then the correlation between the user's and the expert's score was obtained through 
calculations, and the Pearson's correlation coefficient (Pearson's r) was obtained, which represents the correlation intensity between the designer and the user and the quality level of the emotional matching. The positive correlation in the results means that the consumer's feelings are consistent with the effects promoted by the design strategy, while the negative correlation is the opposite. A correlation close to zero is considered irrelevant (Table 10).

Table 10. Correlation matching analysis results.

\begin{tabular}{|c|c|c|c|c|c|c|}
\hline Sample & $\mathrm{C}_{1}$ & $\mathrm{C}_{2}$ & $\mathrm{C}_{3}$ & $\begin{array}{l}\text { Product Description } \\
\qquad \mathrm{C}_{4}\end{array}$ & $\mathrm{C}_{5}$ & High Related Category \\
\hline No.4 & & & $0.998^{b}$ & & & $\mathrm{C}_{3}$ \\
\hline No.5 & & $0.998^{b}$ & & & & $\mathrm{C}_{2}$ \\
\hline No.8 & $0.954^{b}$ & & & & & $\mathrm{C}_{1}$ \\
\hline No.10 & & & & $0.982^{b}$ & & $\mathrm{C}_{4}$ \\
\hline No.11 & & $-0.998^{b}$ & & & & $\mathrm{C}_{2}$ \\
\hline No.13 & & & & & $0.977^{b}$ & $\mathrm{C}_{5}$ \\
\hline No.15 & & $0.998^{b}$ & & & & $\mathrm{C}_{2}$ \\
\hline No.19 & $1.000^{b}$ & & & & & $\mathrm{C}_{1}$ \\
\hline
\end{tabular}

b Significance is 0.05 level (two-tailed).

In order to define the threshold of the correlation coefficient, some experts have proposed that a correlation greater than 0.8 is usually described as a strong correlation, and a correlation less than 0.5 is usually described as a weak correlation [75]. Hence, the product form design of each smart capsule coffee machine is classified: (1) The design with a correlation analysis coefficient above 0.8 is a high-quality design; (2) the design with a correlation coefficient between $0.5-0.8$ is a medium-quality design; and (3) the design with a correlation coefficient below 0.5 is a low-quality design. It can be seen that the seven smart capsule coffee machines in Table 10, except for sample 11, are all high-quality matching products, while the Pearson's r correlation coefficient of sample 11 is -0.998 , which is a negatively correlated product. Accordingly, through the comparison and analysis of seven high-quality form matching design products (Table 11), the factors that affect the matching quality were explored, which will help industrial designers and manufacturers re-evaluate their product design to improve consumer satisfaction.

Table 11. Designers and users' emotionally match products.

Picture

\subsection{Analyzing the Influence Ranking of the Product Components}

In order to quickly and accurately analyze the key product form items that affect the user's Kansei image, priority ranking of the influence of the product form items on the Kansei words was realized, also considering that the grey correlation analysis takes the grey system of "small sample, poor information" as the research object. Therefore, based on the morphological evaluation indicators of the seven products explored above, a grey analysis model was constructed to establish the quantitative relationship between the morphological characteristics of the smart capsule coffee machine and the user Kansei image. Firstly, it is necessary to analyze the product form characteristics, to select 10 people to form a research team, including three designers, five industrial design graduate students, and two design teachers. Using the morphological analysis method to analyze and extract the design elements of the seven research samples, the design elements and category characteristics of the smart capsule coffee machine products were summarized. According to the survey 
results, the six main morphological items (indicated as X1 $\sim$ X6) and the related specific modeling design elements were effectively extracted (see Table 12).

Table 12. Form decomposition of the smart capsule coffee machine products.

\begin{tabular}{|c|c|c|c|c|c|c|c|}
\hline Item & \multicolumn{7}{|c|}{ Design Element Category Display } \\
\hline Top cover & & & & & & & Other \\
\hline $\mathrm{X}_{1}$ & $\mathrm{X}_{11}$ & $\mathrm{X}_{12}$ & & $\mathrm{X}_{14}$ & $X_{15}$ & $x_{16}$ & $\mathrm{X}_{17}$ \\
\hline Body & & & & & & & \\
\hline$x_{2}$ & $X_{21}$ & $X_{22}$ & $X_{23}$ & $X_{24}$ & $X_{25}$ & & \\
\hline Waste water tra & & & & & & & \\
\hline$x_{3}$ & $x_{31}$ & $x_{32}$ & $x_{33}$ & & & & \\
\hline Bottom seat & 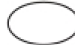 & & & Other & & & \\
\hline $\mathrm{X}_{4}$ & $X_{41}$ & $X_{42}$ & $\mathrm{X}_{43}$ & $\mathrm{X}_{44}$ & & & \\
\hline Water tank & & & & & Other & & \\
\hline$X_{5}$ & $X_{51}$ & $X_{52}$ & $X_{53}$ & $X_{54}$ & $X_{55}$ & & \\
\hline Overall style & & & & & (0) & & \\
\hline$x_{6}$ & $x_{61}$ & $x_{62}$ & $x_{63}$ & $x_{64}$ & $x_{65}$ & $x_{66}$ & \\
\hline
\end{tabular}

Furthermore, a product (sample 17) was added after asking the opinions of the research team, so the number of samples was increased to eight. Then, 30 users and designers were investigated by a 7-level semantic difference method (SD) questionnaire based on these six styling items of eight samples for the exquisite and simple, personalized and fashionable, and dynamic and flexible three product Kansei semantic spaces. The sample average method was utilized to obtain the average value. The specific survey was conducted through an online questionnaire website. Subsequently, the result of the Kansei image survey for personalized and fashionable and the corresponding score values of each sample modeling element were finally calculated (see Table 13).

Table 13. Kansei evaluation value of the products and design elements (Personalized and Fashionable).

\begin{tabular}{|c|c|c|c|c|c|c|c|c|c|}
\hline \multicolumn{2}{|c|}{ Sample Number } & 1 & 2 & 3 & 4 & 5 & 6 & 7 & 8 \\
\hline Kansei word & $\begin{array}{l}\text { Personalized and } \\
\text { Fashionable }\end{array}$ & 1.61 & 1.52 & 2.29 & 2.70 & 2.32 & 1.59 & 1.43 & 1.39 \\
\hline \multirow{6}{*}{$\begin{array}{l}\text { Product } \\
\text { modeling } \\
\text { element }\end{array}$} & $\mathrm{X} 1$ & 0.8 & 1.2 & 1.85 & 2.15 & 1.75 & 1.55 & 1.15 & 0.65 \\
\hline & $\mathrm{X} 2$ & 1.2 & 1.1 & 2.15 & 2.55 & 2.15 & 1.45 & 1.15 & 1.2 \\
\hline & $\mathrm{X} 3$ & 1 & 1 & 1.8 & 1.35 & 1.6 & 1 & 0.55 & 1 \\
\hline & $\mathrm{X} 4$ & 0.75 & 0.8 & 1.3 & 1.25 & 1.5 & 1 & 0.85 & 1.1 \\
\hline & $\mathrm{X} 5$ & 0.85 & 0.8 & 2.3 & 2.15 & 2.5 & 1.95 & 0.6 & 0.6 \\
\hline & $\mathrm{X} 6$ & 1.2 & 1.4 & 2.3 & 2.65 & 2.5 & 1.5 & 1.35 & 1.25 \\
\hline
\end{tabular}

Accordingly, the grey correlation degree between the products' modeling items and Kansei images was calculated and prioritized. To refer to the previous literature [51], the identification coefficient $\xi$ value was set to 0.5 in this study to obtain the ranking results of the importance for the influence degree of the modeling items (see Figures 4 and 5). The sorting results show that the resultant rank sequence of the form parameters shown in Figure 4a can be obtained: X6 > X2 > X1 > X5 > X4 > X3; for the second Kansei word pair, stylish and personalized, the resultant rank sequence shown in Figure $4 \mathrm{~b}$ is obtained as 
X6 $>$ X2 $>$ X1 > X5 > X3 > X4; and for the third Kansei word pair, dynamic and flexible, the resultant rank sequence shown in Figure $4 \mathrm{c}$ is obtained as X6 $>$ X2 $>$ X5 $>$ X1 $>$ X4 $>$ X3.

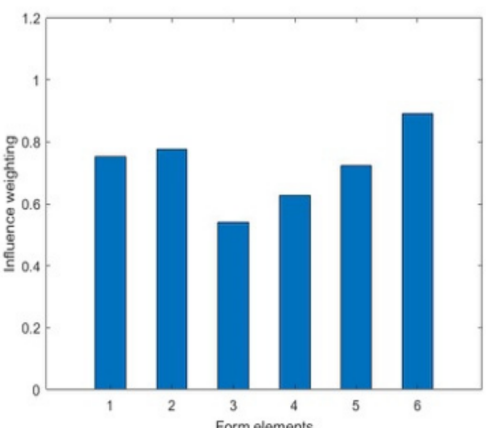

(a)

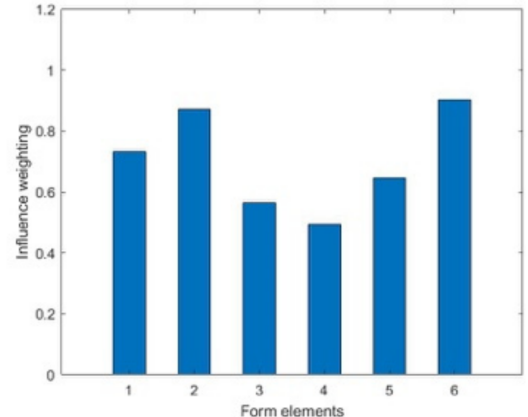

(b)

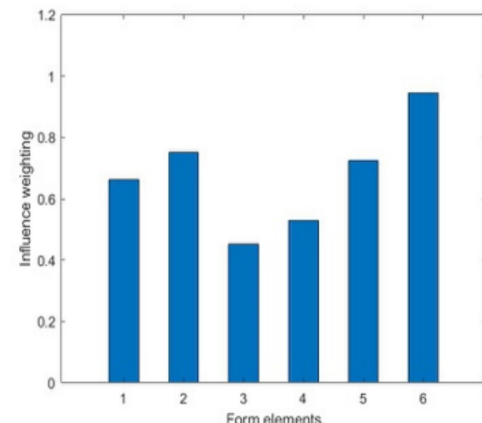

(c)

Figure 4. The influence ranking of the form elements on three Kansei images. (a) Concise and simple; (b) personalized and fashionable; (c) dynamic and flexible.

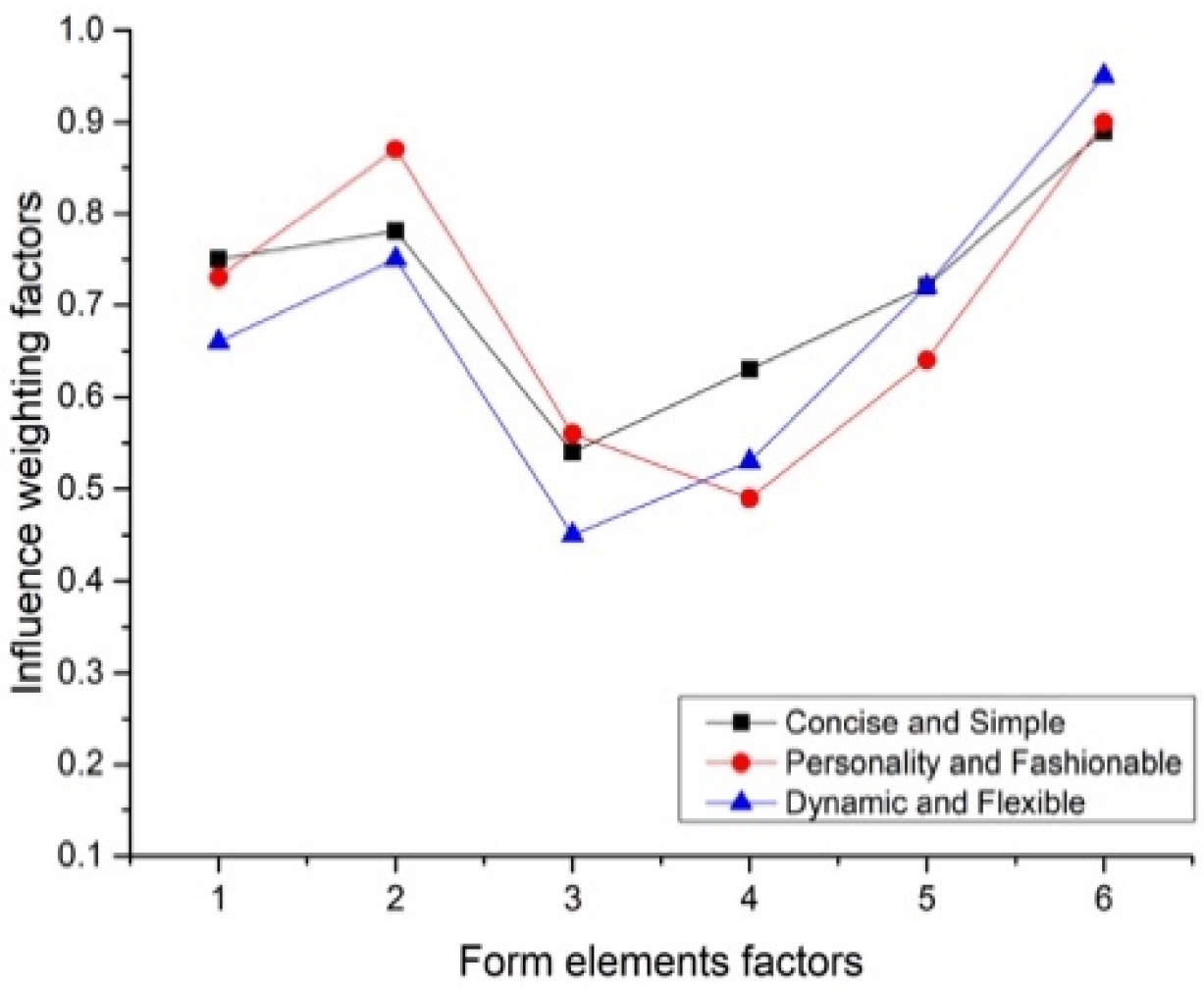

Figure 5. The influence ranking of the form elements.

From these rank sequence results, it is seen that $\mathrm{X} 1, \mathrm{X} 2$, and $\mathrm{X} 6$ are closely related to three Kansei images words, among which X6 has the highest influence value among these three Kansei images, and the influence of X1 and X2 is always smaller than X6; other form elements of the product showed varying degrees of influence, depending on which Kansei words were taken into consideration. Since X 5 could rank fourth in the exquisite and simple, personalized and fashionable Kansei image, and rank third in the dynamic and flexible Kansei image, there is a certain degree of relevance between its item characteristics and product Kansei image. Therefore, the $\mathrm{X} 5$ is also the key factor in the design of the coffee machine. However, some projects $(X 3, X 4)$ have relatively little contribution to the product's Kansei intentions, and the lower ranked formal elements may be ignored. Accordingly, in order to make smart capsule coffee machine products present exquisite 
and simple, personalized and fashionable, and dynamic and flexible of Kansei images, it is necessary to focus on designing the $\mathrm{X} 1, \mathrm{X} 2, \mathrm{X} 5$, and $\mathrm{X} 6$ styling feature items of the product.

\subsection{Product form Evaluation Index Construction}

The $X 1, X 2, X 5$, and $X 6$ index form items of the smart capsule coffee machine have the most significant influence on the overall form of production. Therefore, we interviewed five designers for the key strategies of four parts for the product design plan. Thus, the design method of the product was explored. At the same time, in order to avoid similar or repeated cases among the result indicators obtained from the interview, which would affect the effectiveness of the evaluation, the $\mathrm{KJ}$ method is used to merge similar categories further, and then 19 evaluation indicators for the morphological characteristic elements of the smart capsule coffee machines were constructed (see Table 14). Based on these 19 indicators, the pros and cons of the product plan can be further analyzed.

Table 14. Evaluation index of the morphological elements of the smart capsule coffee machine.

\begin{tabular}{|c|c|c|}
\hline Components & Category & Evaluation Index \\
\hline \multirow{5}{*}{$\begin{array}{l}\text { Upper body } \\
\qquad\left(S_{1}\right)\end{array}$} & $\mathrm{S}_{11}$ & Upper morphological image \\
\hline & $\mathrm{S}_{12}$ & The ratio of the upper body to the fuselage \\
\hline & $\mathrm{S}_{13}$ & Interface button layout \\
\hline & $\mathrm{S}_{14}$ & Interface location \\
\hline & $\mathrm{S}_{15}$ & Outlet shape style \\
\hline \multirow{7}{*}{$\begin{array}{l}\text { Body } \\
\left(S_{2}\right)\end{array}$} & $\mathrm{S}_{16}$ & The ratio of the water outlet to the upper part of the whole \\
\hline & $\mathrm{S}_{21}$ & The outline of the fuselage \\
\hline & $\mathrm{S}_{22}$ & The shape style of the fuselage \\
\hline & $\mathrm{S}_{23}$ & Morphological image of the fuselage \\
\hline & $\mathrm{S}_{24}$ & The ratio of the fuselage to the overall shape \\
\hline & $\mathrm{S}_{25}$ & Decorative pattern \\
\hline & $\mathrm{S}_{31}$ & Main body style \\
\hline \multirow{4}{*}{$\begin{array}{l}\text { Overall style } \\
\qquad\left(\mathrm{S}_{3}\right)\end{array}$} & $\mathrm{S}_{32}$ & Body trend \\
\hline & $\mathrm{S}_{33}$ & Body-scale relationship \\
\hline & $\mathrm{S}_{34}$ & Morphological image \\
\hline & $\mathrm{S}_{35}$ & Unity of function and style \\
\hline \multirow{3}{*}{$\begin{array}{l}\text { Water tank } \\
\qquad\left(\mathrm{S}_{4}\right)\end{array}$} & $\mathrm{S}_{41}$ & The ratio of the water tank to the whole body \\
\hline & $\mathrm{S}_{42}$ & $\begin{array}{c}\text { The degree of coordination between the shape of the water tank } \\
\text { and the overall style }\end{array}$ \\
\hline & $\mathrm{S}_{43}$ & The position relationship between the water tank and the whole \\
\hline
\end{tabular}

\subsection{Computing the Importance of Indicators}

A decision-making group composed of 10 users and design experts carried out investigations on the above 19 indicators, and normalized the survey questionnaire results of these 19 evaluation indicators with 8 samples to construct a decision matrix and then obtain the entropy results of each indicator, to finally get the weight of the 19 indicators (see Table 15). For convenience, the results of the core features of importance are demonstrated in Figure 6. At the same time, the target image weight results are further converted into triangular fuzzy numbers. As indicated by Table 16, the conversion scale of the image weights is determined, so that the results are more in line with the cognitive thinking characteristics of the users. 
Table 15. Index weight.

\begin{tabular}{ccccc}
\hline $\mathbf{X}_{\mathbf{1}}$ & $\mathbf{X}_{\mathbf{2}}$ & $\mathbf{X}_{\mathbf{3}}$ & $\mathbf{X}_{\mathbf{4}}$ & $\mathbf{X}_{\mathbf{5}}$ \\
\hline 0.07 & 0.03 & 0.04 & 0.04 & 0.03 \\
$\mathrm{X}_{6}$ & $\mathrm{X}_{7}$ & $\mathrm{X}_{8}$ & $\mathrm{X}_{\mathbf{9}}$ & $\mathrm{X}_{10}$ \\
0.03 & 0.08 & 0.09 & 0.09 & 0.04 \\
$\mathrm{X}_{11}$ & $\mathrm{X}_{12}$ & $\mathrm{X}_{13}$ & $\mathrm{X}_{14}$ & $\mathrm{X}_{15}$ \\
0.07 & 0.04 & 0.04 & 0.03 & 0.09 \\
$\mathrm{X}_{16}$ & $\mathrm{X}_{17}$ & $\mathrm{X}_{18}$ & $\mathrm{X}_{19}$ & $/$ \\
0.03 & 0.04 & 0.04 & 0.08 & $/$ \\
\hline
\end{tabular}

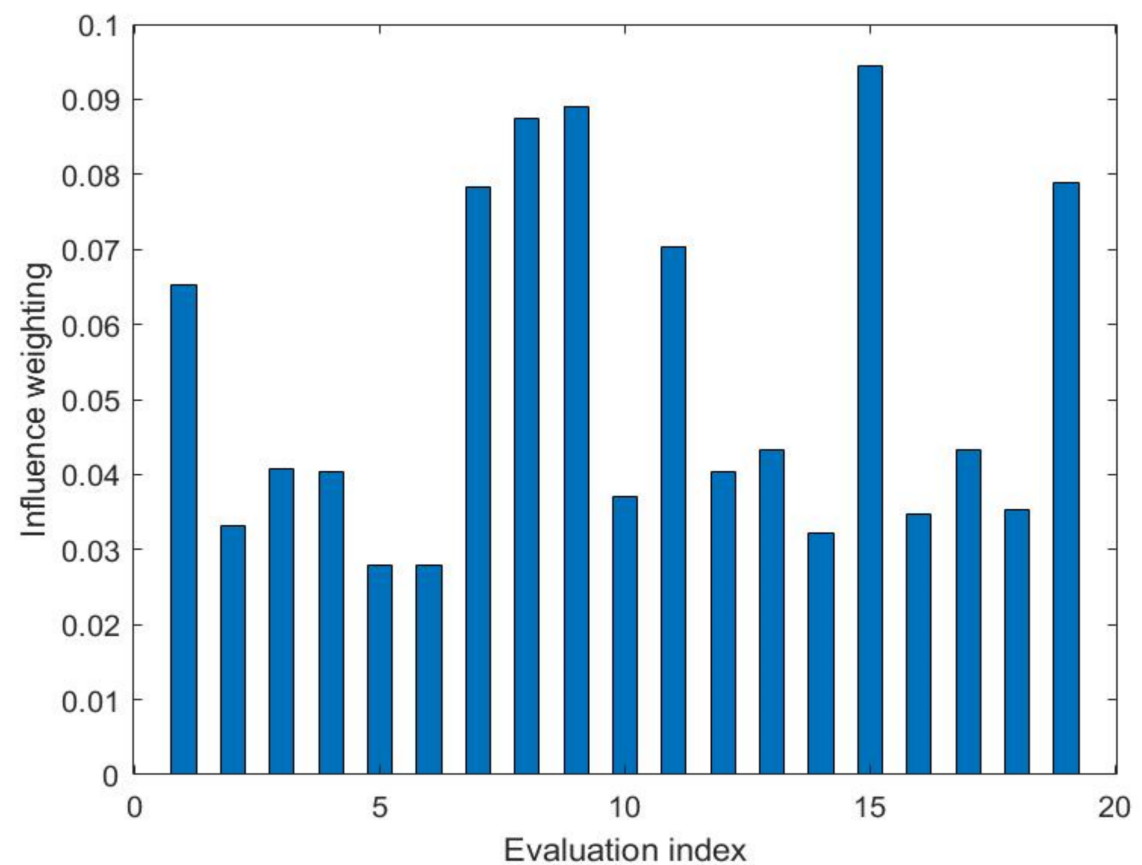

Figure 6. Importance of the 19 indicators.

Table 16. The weight is converted to a fuzzy rating.

\begin{tabular}{cc}
\hline Weight Variable & Fuzzy Rating \\
\hline $0.01-0.02$ & $(1,1,3)$ \\
$0.02-0.05$ & $(1,3,5)$ \\
$0.05-0.07$ & $(3,5,7)$ \\
$0.07-0.09$ & $(5,7,9)$ \\
$0.1-0.2$ & $(7,9,9)$ \\
\hline
\end{tabular}

\subsection{Product Priority Decision-Making}

According to the fuzzy rating standards corresponding to the language variables in Table 16, 33 decision makers composed of 6 design teachers, 5 product managers, and 22 industrial design graduate students began to evaluate 10 smart capsule coffee machine product design schemes $\left(\mathrm{P}_{1}, \mathrm{P}_{2}, \mathrm{P}_{3}, \mathrm{P}_{4}, \mathrm{P}_{5}, \mathrm{P}_{6}, \mathrm{P}_{7}, \mathrm{P}_{8}, \mathrm{P}_{9}, \mathrm{P}_{10}\right)$ based on 19 evaluation indicators (also see Table 14). In order to minimize the uncertain factors of information and make the evaluation results more objective and accurate, the language variables were directly converted into triangular fuzzy numbers (see Table 17), and the weighted overall evaluation of the 33 decision makers was obtained according to Equations (13)-(19). 
Table 17. Fuzzy rating of the schemes corresponding to the linguistic variables.

\begin{tabular}{cc}
\hline Linguistic Variables & Fuzzy Rating \\
\hline Very bad & $(1,1,3)$ \\
Bad & $(1,3,5)$ \\
General & $(3,5,7)$ \\
Good & $(5,7,9)$ \\
Very good & $(7,9,9)$ \\
\hline
\end{tabular}

According to Equations (22) and (23), the distance between the new sample and the fuzzy optimal solution and the worst solution can be obtained (see tables 18 and 19). According to Equation (25), the relative closeness between the new sample and the ideal solution can be obtained, and it is demonstrated in Table 20 (also see Figure 7), so the priority order of the 10 smart capsule coffee machine product samples is $\mathrm{P}_{8}>\mathrm{P}_{7}>\mathrm{P}_{9}>\mathrm{P}_{1}$ $>\mathrm{P}_{5}>\mathrm{P}_{6}>\mathrm{P}_{2}>\mathrm{P}_{3}>\mathrm{P}_{4}>\mathrm{P}_{10}$. Based on this, the sample of the best solution for product modeling design is $\mathrm{P}_{8}$, followed by $\mathrm{P}_{7}$, and again $\mathrm{P}_{9}$. Therefore, $\mathrm{P}_{8}$ is established as the optimal form design scheme of the smart capsule coffee machine.

Table 18. The distance between the scheme and the fuzzy optimal solution.

\begin{tabular}{ccccccccccc}
\hline Criterion & $\mathbf{P}_{\mathbf{1}}$ & $\mathbf{P}_{\mathbf{2}}$ & $\mathbf{P}_{\mathbf{3}}$ & $\mathbf{P}_{\mathbf{4}}$ & $\mathbf{P}_{\mathbf{5}}$ & $\mathbf{P}_{\mathbf{6}}$ & $\mathbf{P}_{\mathbf{7}}$ & $\mathbf{P}_{\mathbf{8}}$ & $\mathbf{P}_{\mathbf{9}}$ & $\mathbf{P}_{\mathbf{1 0}}$ \\
\hline $\mathbf{X}_{1}$ & 6.105 & 7.322 & 7.347 & 7.365 & 7.315 & 7.309 & 5.486 & 5.474 & 5.474 & 7.365 \\
$\mathbf{X}_{2}$ & 6.032 & 7.328 & 7.347 & 7.384 & 7.347 & 7.309 & 5.425 & 5.367 & 5.425 & 7.365 \\
$\mathbf{X}_{\mathbf{3}}$ & 6.115 & 7.328 & 7.359 & 7.378 & 7.291 & 7.334 & 5.449 & 5.425 & 5.486 & 7.365 \\
$\mathbf{X}_{4}$ & 6.115 & 7.353 & 7.315 & 7.365 & 7.291 & 7.309 & 5.425 & 5.401 & 5.437 & 7.372 \\
$\mathbf{X}_{5}$ & 6.032 & 7.353 & 7.353 & 7.365 & 7.334 & 7.334 & 5.524 & 5.437 & 5.537 & 7.416 \\
$\mathbf{X}_{6}$ & 6.022 & 7.334 & 7.391 & 7.378 & 7.334 & 7.340 & 5.499 & 5.390 & 5.461 & 7.365 \\
$\mathbf{X}_{7}$ & 5.674 & 7.365 & 7.372 & 7.378 & 7.284 & 7.315 & 5.425 & 5.437 & 5.461 & 7.372 \\
$\mathbf{X}_{8}$ & 5.972 & 7.347 & 7.365 & 7.372 & 7.309 & 7.340 & 5.461 & 5.486 & 5.461 & 7.365 \\
$\mathbf{X}_{9}$ & 6.012 & 7.334 & 7.365 & 7.391 & 7.309 & 7.334 & 5.486 & 5.449 & 5.524 & 7.378 \\
$\mathbf{X}_{10}$ & 5.962 & 7.340 & 7.372 & 7.353 & 7.303 & 7.347 & 5.437 & 5.401 & 5.437 & 7.404 \\
$\mathbf{X}_{11}$ & 6.063 & 7.359 & 7.404 & 7.429 & 7.365 & 7.322 & 5.486 & 5.499 & 5.499 & 7.391 \\
$\mathbf{X}_{12}$ & 5.992 & 7.353 & 7.384 & 7.384 & 7.309 & 7.328 & 5.461 & 5.461 & 5.425 & 7.340 \\
$\mathbf{X}_{13}$ & 5.992 & 7.365 & 7.378 & 7.391 & 7.328 & 7.309 & 5.437 & 5.486 & 5.461 & 7.416 \\
$\mathbf{X}_{14}$ & 5.972 & 7.347 & 7.365 & 7.359 & 7.328 & 7.309 & 5.401 & 5.425 & 5.449 & 7.378 \\
$\mathbf{X}_{15}$ & 6.022 & 7.322 & 7.359 & 7.384 & 7.315 & 7.309 & 5.486 & 5.437 & 5.461 & 7.397 \\
$\mathbf{X}_{16}$ & 6.032 & 7.322 & 7.359 & 7.347 & 7.340 & 7.309 & 5.461 & 5.474 & 5.461 & 7.359 \\
$\mathbf{X}_{17}$ & 6.053 & 7.347 & 7.353 & 7.391 & 7.303 & 7.347 & 5.449 & 5.461 & 5.499 & 7.416 \\
$\mathbf{X}_{18}$ & 6.022 & 7.378 & 7.378 & 7.384 & 7.291 & 7.309 & 5.461 & 5.437 & 5.486 & 7.391 \\
$\mathbf{X}_{19}$ & 6.053 & 7.384 & 7.372 & 7.378 & 7.315 & 7.322 & 5.449 & 5.461 & 5.499 & 7.416 \\
\hline
\end{tabular}

\subsection{Sensitivity Analysis}

In order to further study the evaluation process of the fuzzy TOPSIS method, based on the entropy fuzzy number, a sensitivity analysis was carried out to change the product evaluation standard weight. Specifically, the criterion weight obtained from the entropybased and fuzzy evaluation was used for the change operation. In each round of sensitivity analysis, the weights of the two evaluation criteria were exchanged, while the weights of the other criteria remain the same. Then, the new standard weight was combined with TOPSIS based on the fuzzy number to sort the candidates. Referring to the previously published literature [11], only the weight of the first evaluation standard was used to exchange sequentially with other standards. In the first round (Z1), the original weights, $\mathrm{w}_{1}, \mathrm{w}_{2}, \mathrm{w}_{18}$, and $\mathrm{w}_{19}$, were used as the evaluation criteria. In the second round (Z2), the weights of criteria $S_{11}$ and $S_{12}$ were exchanged, and then the standard weights were changed to $\mathrm{w}_{2}, \mathrm{w}_{1}, \mathrm{w}_{18}$, and $\mathrm{w}_{19}$. Similarly, in the 19th round (Z19), the weights of the standards $S_{11}$ and $S_{43}$ were exchanged, and the new standard weights obtained were $w_{19}$, $\mathrm{w}_{2}, \mathrm{w}_{18}$, and $\mathrm{w}_{1}$. Based on these assumptions, the detailed sensitivity analysis results are shown in Table 21 and Figure 8. 
Table 19. The distance between the scheme and the fuzzy worst solution.

\begin{tabular}{ccccccccccc}
\hline Criterion & $\mathbf{P}_{\mathbf{1}}$ & $\mathbf{P}_{\mathbf{2}}$ & $\mathbf{P}_{\mathbf{3}}$ & $\mathbf{P}_{\mathbf{4}}$ & $\mathbf{P}_{\mathbf{5}}$ & $\mathbf{P}_{\mathbf{6}}$ & $\mathbf{P}_{\mathbf{7}}$ & $\mathbf{P}_{\mathbf{8}}$ & $\mathbf{P}_{\mathbf{9}}$ & $\mathbf{P}_{\mathbf{1 0}}$ \\
\hline $\mathrm{X}_{1}$ & 4.380 & 2.069 & 2.042 & 2.022 & 2.076 & 2.083 & 5.766 & 5.779 & 5.779 & 2.022 \\
$\mathrm{X}_{2}$ & 4.439 & 2.062 & 2.042 & 2.002 & 2.042 & 2.083 & 5.829 & 5.895 & 5.829 & 2.022 \\
$\mathrm{X}_{3}$ & 4.372 & 2.062 & 2.029 & 2.009 & 2.104 & 2.056 & 5.804 & 5.829 & 5.766 & 2.022 \\
$\mathrm{X}_{4}$ & 4.372 & 2.035 & 2.076 & 2.022 & 2.104 & 2.083 & 5.829 & 5.855 & 5.816 & 2.015 \\
$\mathrm{X}_{5}$ & 4.439 & 2.035 & 2.035 & 2.022 & 2.056 & 2.056 & 5.730 & 5.816 & 5.718 & 1.971 \\
$\mathrm{X}_{6}$ & 4.448 & 2.056 & 1.996 & 2.009 & 2.056 & 2.049 & 5.754 & 5.868 & 5.791 & 2.022 \\
$\mathrm{X}_{7}$ & 4.502 & 2.022 & 2.015 & 2.009 & 2.111 & 2.076 & 5.829 & 5.816 & 5.791 & 2.015 \\
$\mathrm{X}_{8}$ & 4.492 & 2.042 & 2.022 & 2.015 & 2.083 & 2.049 & 5.791 & 5.766 & 5.791 & 2.022 \\
$\mathrm{X}_{9}$ & 4.456 & 2.056 & 2.022 & 1.996 & 2.083 & 2.056 & 5.766 & 5.804 & 5.730 & 2.009 \\
$\mathrm{X}_{10}$ & 4.501 & 2.049 & 2.015 & 2.035 & 2.090 & 2.042 & 5.816 & 5.855 & 5.816 & 1.983 \\
$\mathrm{X}_{11}$ & 4.414 & 2.029 & 1.983 & 1.958 & 2.022 & 2.069 & 5.766 & 5.754 & 5.754 & 1.996 \\
$\mathrm{X}_{12}$ & 4.474 & 2.035 & 2.002 & 2.002 & 2.083 & 2.062 & 5.791 & 5.791 & 5.829 & 2.049 \\
$\mathrm{X}_{13}$ & 4.474 & 2.022 & 2.009 & 1.996 & 2.062 & 2.083 & 5.816 & 5.766 & 5.791 & 1.971 \\
$\mathrm{X}_{14}$ & 4.492 & 2.042 & 2.022 & 2.029 & 2.062 & 2.083 & 5.855 & 5.829 & 5.804 & 2.009 \\
$\mathrm{X}_{15}$ & 4.448 & 2.069 & 2.029 & 2.002 & 2.076 & 2.083 & 5.766 & 5.816 & 5.791 & 1.990 \\
$\mathrm{X}_{16}$ & 4.439 & 2.069 & 2.029 & 2.042 & 2.049 & 2.083 & 5.791 & 5.779 & 5.791 & 2.029 \\
$\mathrm{X}_{17}$ & 4.422 & 2.042 & 2.035 & 1.996 & 2.090 & 2.042 & 5.804 & 5.791 & 5.754 & 1.971 \\
$\mathrm{X}_{18}$ & 4.448 & 2.009 & 2.009 & 2.002 & 2.104 & 2.083 & 5.791 & 5.816 & 5.766 & 1.996 \\
$\mathrm{X}_{19}$ & 4.422 & 2.002 & 2.015 & 2.009 & 2.076 & 2.069 & 5.804 & 5.791 & 5.754 & 1.971 \\
\hline
\end{tabular}

Table 20. The relative closeness between the alternative solution and the ideal solution.

\begin{tabular}{ccccccccccc}
\hline \multicolumn{10}{c}{ Alternative Design Sample } \\
\hline Index & $\mathbf{P}_{\mathbf{1}}$ & $\mathbf{P}_{\mathbf{2}}$ & $\mathbf{P}_{\mathbf{3}}$ & $\mathbf{P}_{\mathbf{4}}$ & $\mathbf{P}_{\mathbf{5}}$ & $\mathbf{P}_{\mathbf{6}}$ & $\mathbf{P}_{\mathbf{7}}$ & $\mathbf{P}_{\mathbf{8}}$ & $\mathbf{P}_{\mathbf{9}}$ & $\mathbf{P}_{\mathbf{1 0}}$ \\
\hline$d_{i}{ }^{+}$ & 114.24 & 139.58 & 139.94 & 140.18 & 139.01 & 139.13 & 103.71 & 103.41 & 103.94 & 140.27 \\
$d i^{-}$ & 84.43 & 38.81 & 38.43 & 38.18 & 39.43 & 39.29 & 110.10 & 110.42 & 109.86 & 38.08 \\
$C_{i}$ & 0.4250 & 0.2175 & 0.2154 & 0.2141 & 0.2210 & 0.2202 & 0.5149 & 0.5164 & 0.5138 & 0.2135 \\
Rank & 4 & 7 & 8 & 9 & 5 & 6 & 2 & 1 & 3 & 10 \\
\hline
\end{tabular}

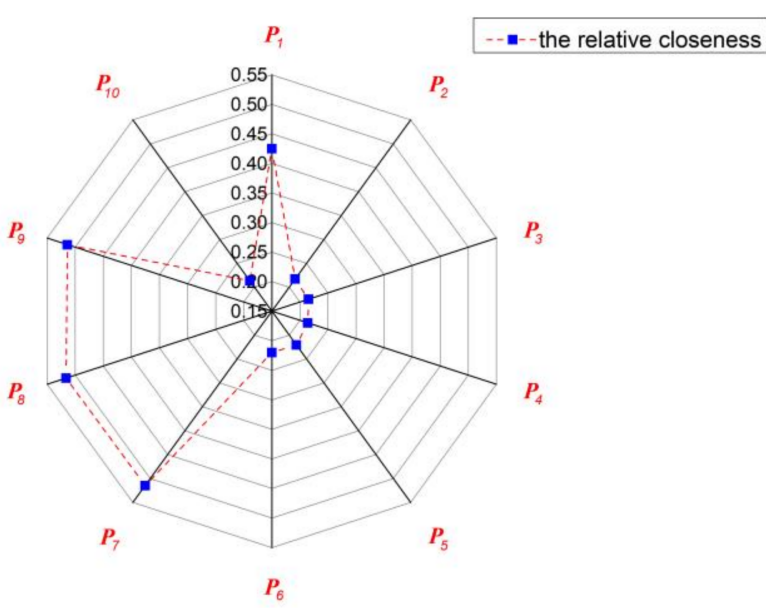

(a)

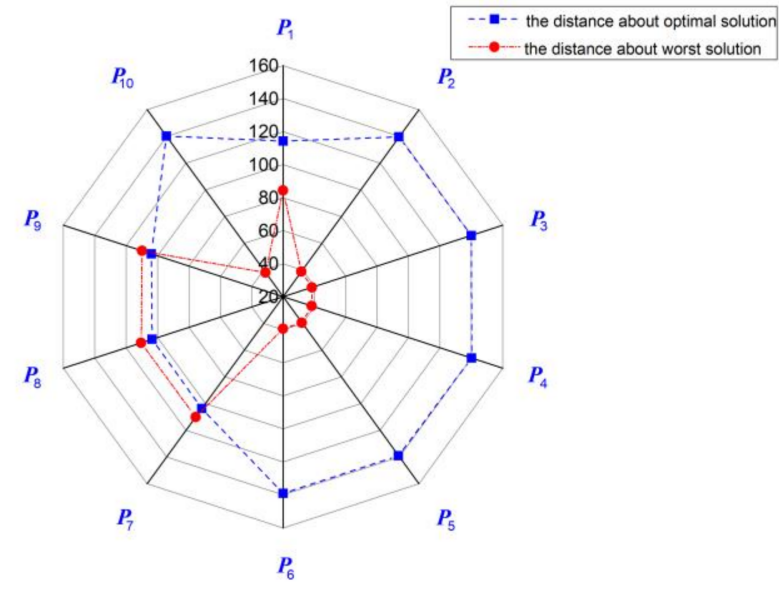

(b)

Figure 7. The closeness of the 10 product solutions. (a) The closeness between solutions and the ideal solution. (b) The distance about optimal and worst solution. 
Table 21. Results of the sensitivity analysis.

\begin{tabular}{|c|c|c|c|c|c|c|c|c|c|c|c|}
\hline \multirow{2}{*}{ No } & \multirow{2}{*}{ Variables } & \multirow[b]{2}{*}{$\mathbf{P}_{1}$} & \multirow[b]{2}{*}{$P_{2}$} & \multirow[b]{2}{*}{$\mathbf{P}_{3}$} & \multicolumn{7}{|c|}{ Alternatives } \\
\hline & & & & & $\mathbf{P}_{4}$ & $\mathbf{P}_{5}$ & $\mathbf{P}_{6}$ & $P_{7}$ & $\mathbf{P}_{8}$ & $\mathbf{P}_{9}$ & $\mathbf{P}_{10}$ \\
\hline \multirow[b]{2}{*}{$\mathrm{Z1}$} & $C_{i}$ & 0.425 & 0.218 & 0.215 & 0.214 & 0.221 & 0.220 & 0.515 & 0.516 & 0.514 & 0.214 \\
\hline & Rank & 4 & 7 & 8 & 9 & 5 & 6 & 2 & 1 & 3 & 10 \\
\hline \multirow{2}{*}{$\mathrm{Z} 2$} & $C_{i}$ & 0.216 & 0.426 & 0.215 & 0.214 & 0.221 & 0.220 & 0.515 & 0.516 & 0.514 & 0.214 \\
\hline & Rank & 7 & 4 & 8 & 9 & 5 & 6 & 2 & 1 & 3 & 10 \\
\hline \multirow{2}{*}{$\mathrm{Z} 3$} & $C_{i}$ & 0.216 & 0.218 & 0.423 & 0.214 & 0.221 & 0.220 & 0.515 & 0.516 & 0.514 & 0.214 \\
\hline & Rank & 8 & 7 & 4 & 9 & 5 & 6 & 2 & 1 & 3 & 10 \\
\hline \multirow{2}{*}{$\mathrm{Z4}$} & $C_{i}$ & 0.216 & 0.218 & 0.215 & 0.421 & 0.221 & 0.220 & 0.515 & 0.516 & 0.514 & 0.214 \\
\hline & Rank & 8 & 7 & 9 & 4 & 5 & 6 & 2 & 1 & 3 & 10 \\
\hline \multirow{2}{*}{$\mathrm{Z} 5$} & $C_{i}$ & 0.216 & 0.218 & 0.215 & 0.214 & 0.430 & 0.220 & 0.515 & 0.516 & 0.514 & 0.214 \\
\hline & Rank & 7 & 6 & 8 & 9 & 4 & 5 & 2 & 1 & 3 & 10 \\
\hline \multirow[b]{2}{*}{ Z6 } & $C_{i}$ & 0.216 & 0.218 & 0.215 & 0.214 & 0.221 & 0.429 & 0.515 & 0.516 & 0.514 & 0.214 \\
\hline & Rank & 7 & 6 & 8 & 9 & 5 & 4 & 2 & 1 & 3 & 10 \\
\hline \multirow[b]{2}{*}{$\mathrm{Z7}$} & $C_{i}$ & 0.521 & 0.218 & 0.215 & 0.214 & 0.221 & 0.220 & 0.421 & 0.516 & 0.514 & 0.214 \\
\hline & Rank & 1 & 7 & 8 & 9 & 5 & 6 & 4 & 2 & 3 & 10 \\
\hline \multirow[b]{2}{*}{ Z8 } & $C_{i}$ & 0.521 & 0.218 & 0.215 & 0.214 & 0.221 & 0.220 & 0.515 & 0.422 & 0.514 & 0.214 \\
\hline & Rank & 1 & 7 & 8 & 9 & 5 & 6 & 2 & 4 & 3 & 10 \\
\hline \multirow{2}{*}{ Z9 } & $C_{i}$ & 0.521 & 0.218 & 0.215 & 0.214 & 0.221 & 0.220 & 0.515 & 0.516 & 0.420 & 0.214 \\
\hline & Rank & 1 & 7 & 8 & 9 & 5 & 6 & 3 & 2 & 4 & 10 \\
\hline \multirow[b]{2}{*}{ Z10 } & $C_{i}$ & 0.216 & 0.218 & 0.215 & 0.214 & 0.221 & 0.220 & 0.515 & 0.516 & 0.514 & 0.421 \\
\hline & Rank & 8 & 7 & 9 & 10 & 5 & 6 & 2 & 1 & 3 & 4 \\
\hline \multirow{2}{*}{ Z11 } & $C_{i}$ & 0.521 & 0.218 & 0.215 & 0.214 & 0.221 & 0.220 & 0.515 & 0.516 & 0.514 & 0.214 \\
\hline & Rank & 1 & 7 & 8 & 9 & 5 & 6 & 3 & 2 & 4 & 10 \\
\hline \multirow{2}{*}{ Z12 } & $C_{i}$ & 0.216 & 0.218 & 0.215 & 0.214 & 0.221 & 0.220 & 0.515 & 0.516 & 0.514 & 0.214 \\
\hline & Rank & 7 & 6 & 8 & 9 & 4 & 5 & 2 & 1 & 3 & 10 \\
\hline \multirow{2}{*}{ Z13 } & $C_{i}$ & 0.216 & 0.218 & 0.215 & 0.214 & 0.221 & 0.220 & 0.515 & 0.516 & 0.514 & 0.214 \\
\hline & Rank & 7 & 6 & 8 & 9 & 4 & 5 & 2 & 1 & 3 & 10 \\
\hline \multirow{2}{*}{ Z14 } & $C_{i}$ & 0.216 & 0.218 & 0.215 & 0.214 & 0.221 & 0.220 & 0.515 & 0.516 & 0.514 & 0.214 \\
\hline & Rank & 7 & 6 & 8 & 9 & 4 & 5 & 2 & 1 & 3 & 10 \\
\hline \multirow{2}{*}{ Z15 } & $C_{i}$ & 0.560 & 0.218 & 0.215 & 0.214 & 0.221 & 0.220 & 0.515 & 0.516 & 0.514 & 0.214 \\
\hline & Rank & 1 & 7 & 8 & 9 & 5 & 6 & 3 & 2 & 4 & 10 \\
\hline \multirow{2}{*}{ Z16 } & $C_{i}$ & 0.216 & 0.218 & 0.215 & 0.214 & 0.221 & 0.220 & 0.515 & 0.516 & 0.514 & 0.214 \\
\hline & Rank & 7 & 6 & 8 & 9 & 4 & 5 & 2 & 1 & 3 & 10 \\
\hline \multirow{2}{*}{ Z17 } & $C_{i}$ & 0.216 & 0.218 & 0.215 & 0.214 & 0.221 & 0.220 & 0.515 & 0.516 & 0.514 & 0.214 \\
\hline & Rank & 7 & 6 & 8 & 9 & 4 & 5 & 2 & 1 & 3 & 10 \\
\hline & $C_{i}$ & 0.216 & 0.218 & 0.215 & 0.214 & 0.221 & 0.220 & 0.515 & 0.516 & 0.514 & 0.214 \\
\hline 218 & Rank & 7 & 6 & 8 & 9 & 4 & 5 & 2 & 1 & 3 & 10 \\
\hline & $C_{i}$ & 0.521 & 0.218 & 0.215 & 0.214 & 0.221 & 0.220 & 0.515 & 0.516 & 0.514 & 0.214 \\
\hline 219 & Rank & 1 & 7 & 8 & 9 & 5 & 6 & 3 & 2 & 4 & 10 \\
\hline
\end{tabular}

It can be seen from Table 20 and Figure 8 that the relative closeness $(C i)$ of $\mathrm{P}_{8}, \mathrm{P}_{7}$, and $\mathrm{P}_{9}$ is the highest. However, in most evaluation index weight changes, the values of these two options are very close. By changing the weights of the two evaluation criteria, the ranking result does not change much. Therefore, the proposed fuzzy TOPSIS method based on entropy is stable and reliable for the evaluation of design concepts. Specifically, scheme $\mathrm{P}_{8}$ ranked first in the experiment 13 times, so the probability of scheme $\mathrm{P}_{8}$ becoming the first choice accounted for $68.4 \%$. In addition, there are many different change strategies in the sensitivity analysis; we only list the exchanges between criterion $S_{11}$ and other criteria. Furthermore, more extension methods can be introduced to further enhance the sensitivity analysis. 


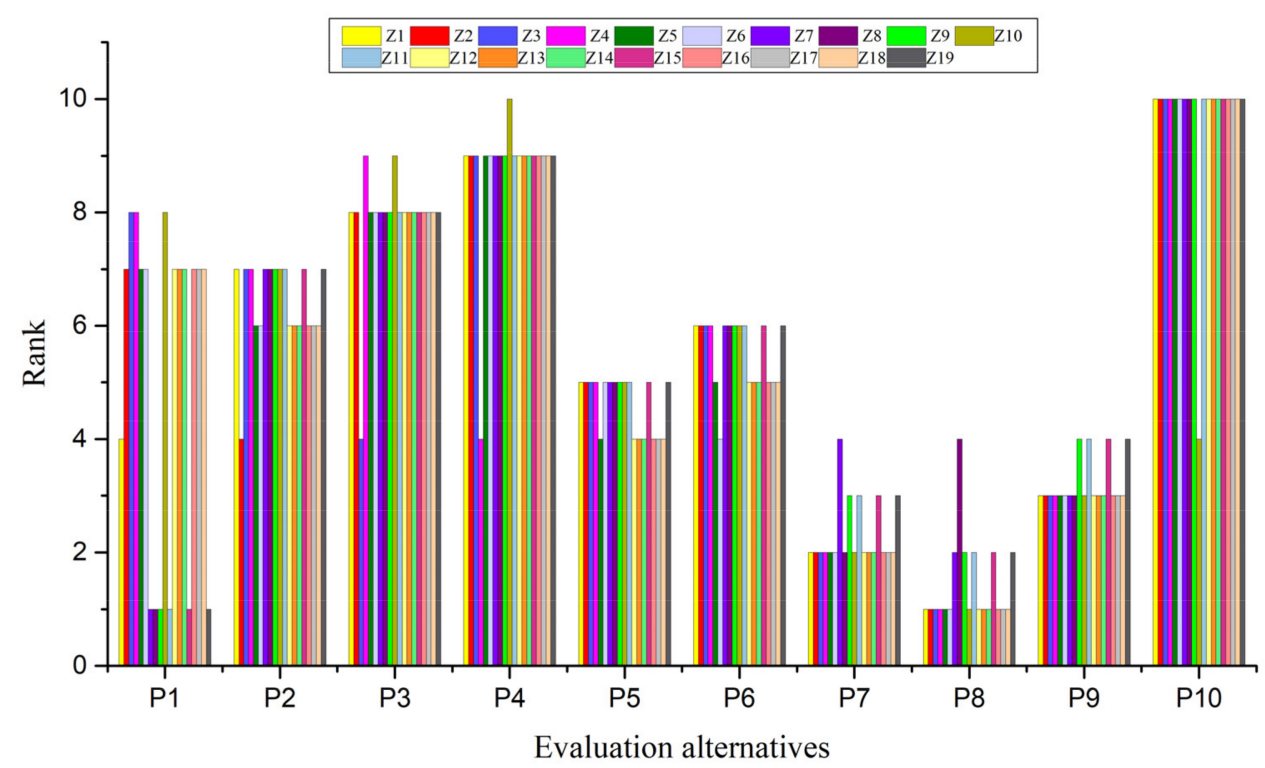

Figure 8. Ranking results of the sensitivity analysis.

\section{Discussion and Conclusions}

In order to survive under global competition and in a fast-changing environment, product development must make product innovations popular with consumers; that is, meet the demands of their target users. This product strategy attempts to customize the best product to adapt to different needs of different markets. In order to realize the symmetry of consumer and designer perceptions and preferences for smart capsule coffee machines, this research proposes a new product design evaluation method that combines natural language processing and the fuzzy TOPSIS method based on Kansei engineering to realize product design making-decision and optimization. The Kansei needs of consumers are crawled from online reviews, and the task of capturing the Kansei intentions of users can be automatically completed based on the natural language processing. Furthermore, the product design elements are quantified, and the key design elements of the product are extracted based on GRA to establish the product evaluation indicators. Moreover, the fuzzy TOPSIS method is used to complete the product priority ranking based on user preferences. Therefore, the design work can be accelerated based on automatic extraction for user Kansei needs, and the uncertainty and subjective manipulation of the design concept evaluation in the group decision-making environment can be solved at the same time, and the objectivity and credibility of the ranking results of the design alternatives can be improved. The main contributions of this article are summarized as follows:

1. In order to meet the needs of users and speed up the product development process, this research proposes a user-driven automated product design framework that integrates text mining and $\mathrm{KE}$ to extract products with symmetrical cognitive information between users and designers, and then to help the company and designer to better complete the product customization and decision-making.

2. For capturing customers' perception of a product's emotional characteristics effectively, a product Kansei image acquisition method based on user network review data is proposed, as well as to mine the users' real evaluation Kansei information from the network review big data in a faster way so as to break away from the interview and questionnaire methods in traditional KE, and to establish a more efficient Kansei design way.

3. Parameterization of the Kansei vocabulary semantic vector through artificial intelligence technology of NLP can effectively avoid the deviation between the real preferences and preferences shown in traditional questionnaire surveys, while saving research time so that designers can perform related value-added work, consequently achieving symmetry between the extracted needs and the real needs of users. 
4. Utilizing GRA to identify the associated features between the user's preferred modeling elements and the Kansei image can predict the importance priority of each design element for the product.

5. Introducing fuzzy theory into the TOPSIS method and using the transformation scale can convert the linguistic variables into triangular fuzzy numbers. Using fuzzy logic can solve the problem of the uncertainty and ambiguity of human thinking, so the accuracy of the experimental results is improved. Thus, the subjectivity of judgment can be avoided.

6. Adopting a T-test and correlation analysis, the products that fit the psychological preference factors of designers and users are extracted precisely, so as to realize the symmetry between the designer and the user's cognitive information.

On the other hand, the limitations of this document are as follows:

1. The current system only collects information from online reviews of e-commerce platforms, which is limited. We should try from more dimensions, and other information extracted from sources such as consumer reports and social media should be included so as to explore the customer need factors from more comprehensive dimensions.

2. The method used in this research is to make decision of the design plan based on the evaluation of existing products in the market. However, there are differences between the conceptual evaluation results of the marketed product and the actual product design plan. In the future, the product evaluation and decision-making in the design concept stage should be explored.

3. What is more, it is necessary to collect and classify more background information from online customers to provide a research path for market segmentation and personalized development and design of products.

In addition, in the process of users' demand acquisition, the relatively old reviews should be weakened. Therefore, in the future, the quantification of the time factor should be integrated into the user demand analysis to make the user demand acquisition more effective. Moreover, the evaluation of products should start from a multi-dimensional perspective, such as structure and material, so as to make the evaluation results more comprehensive for production design.

Funding: This work was supported by the Anhui University talent introduction research start-up funding project (No. S020318019).

Institutional Review Board Statement: Not applicable.

Informed Consent Statement: Not applicable.

Data Availability Statement: The experiment data used to support the findings of this study are included in the article.

Conflicts of Interest: The author declares no conflict of interest.

\section{References}

1. Liu, C.-Y.; Tong, L.-I. Developing Automatic Form and Design System Using Integrated Grey Relational Analysis and Affective Engineering. Appl. Sci. 2018, 8, 91. [CrossRef]

2. Jung, H.; Wiltse, H.; Wiberg, M.; Stolterman, E. Metaphors, materialities, and affordances: Hybrid morphologies in the design of interactive artifacts. Des. Stud. 2017, 53, 24-46. [CrossRef]

3. Kuang, J.; Jiang, P. Product platform design for a product family based on Kansei engineering. J. Eng. Des. 2009, $20,589-607$. [CrossRef]

4. Jiao, J.; Zhang, Y.; Helander, M. A Kansei mining system for affective design. Expert Syst. Appl. 2006, 30, 658-673. [CrossRef]

5. Ding, M.; Bai, Z. Product color emotional design adaptive to product shape feature variation. Color Res. Appl. 2019, 44, 811-823. [CrossRef]

6. Wang, C.-H. Combining rough set theory with fuzzy cognitive pairwise rating to construct a novel framework for developing multi-functional tablets. J. Eng. Des. 2018, 29, 430-448. [CrossRef]

7. Wang, K.-C. A hybrid Kansei engineering design expert system based on grey system theory and support vector regression. Expert Syst. Appl. 2011, 38, 8738-8750. [CrossRef] 
8. Guo, F.; Li, F.; Nagamachi, M.; Hu, M.; Li, M. Research on color optimization of tricolor product considering color harmony and users' emotion. Color Res. Appl. 2019, 45, 156-171. [CrossRef]

9. Wang, W.M.; Wang, J.W.; Li, Z.; Tian, Z.G.; Tsui, E. Multiple affective attribute classification of online customer product reviews: A heuristic deep learning method for supporting Kansei engineering. Eng. Appl. Artif. Intell. 2019, 85, 33-45. [CrossRef]

10. Liu, A.; Xiao, Y.; Lu, H.; Tsai, S.-B.; Song, W. A fuzzy three-stage multi-attribute decision-making approach based on customer needs for sustainable supplier selection. J. Clean. Prod. 2019, 239, 118043. [CrossRef]

11. Zhu, G.-N.; Hu, J.; Ren, H. A fuzzy rough number-based AHP-TOPSIS for design concept evaluation under uncertain environments. Appl. Soft Comput. 2020, 91, 106228. [CrossRef]

12. Zheng, X.; Ritter, S.C.; Miller, S.R. How Concept Selection Tools Impact the Development of Creative Ideas in Engineering Design Education. J. Mech. Des. 2018, 140, 052002. [CrossRef]

13. Dong, A.; Lovallo, D.; Mounarath, R. The effect of abductive reasoning on concept selection decisions. Des. Stud. 2015, 37, 37-58 [CrossRef]

14. Nagamachi, M. Kansei Engineering: A new ergonomic consumer-oriented technology for product development. Int. J. Ind. Ergon. 1995, 15, 3-11. [CrossRef]

15. Nagamachi, M. Kansei Engineering and Rough Sets Model. In Proceedings of the Rough Sets and Current Trends in Computing Proceedings of the 5th International Conference, RSCTC 2006, Kobe, Japan, 6-8 November 2006; Springer: Berlin/Heidelberg, Germany, 2006; pp. 27-37.

16. Xue, L.; Yi, X.; Zhang, Y. Research on Optimized Product Image Design Integrated Decision System Based on Kansei Engineering. Appl. Sci. 2020, 10, 1-19. [CrossRef]

17. Ahmed, W.B.; Yannou, B. A Bayesian learning of probabilistic relations between perceptual attributes and technical characteristics of car dashboards to construct a perceptual evaluation model. Int. J. Prod. Dev. 2009, 7, 47-72. [CrossRef]

18. Shahin, A.; Javadi, M.H.M.; Shahrestani, H.V. Integrating Kansei engineering and revised Kano model with a case study in the automobile industry. Int. J. Product. Qual. Manag. 2014, 13, 201-218. [CrossRef]

19. Zabotto, C.N.; Amaral, D.C.; Hornos CJ, M.; Benze, B.G. Automatic digital mood boards to connect users and designers with kansei engineering. Int. J. Ind. Ergon. 2019, 74, 102829. [CrossRef]

20. Schütte, S.T.W.; Eklund, J.; Axelsson, J.R.C.; Nagamachi, M. Concepts, methods and tools in Kansei engineering. Theor. Issues Ergon. Sci. 2004, 5, 214-231. [CrossRef]

21. Shieh, M.-D.; Li, Y.; Yang, C.-C. Product Form Design Model Based on Multiobjective Optimization and Multicriteria DecisionMaking. Math. Probl. Eng. 2017, 2017. [CrossRef]

22. Seo, K.K.; Park, J.H.; Jang, D.S.; Wallace, D. Approximate Estimation of the Product Life Cycle Cost Using Artificial Neural Networks in Conceptual Design. Int. J. Adv. Manuf. Technol. 2002, 19, 461-471. [CrossRef]

23. Li, M.; Jin, L.; Wang, J. A new MCDM method combining QFD with TOPSIS for knowledge management system selection from the user's perspective in intuitionistic fuzzy environment. Appl. Soft Comput. 2014, 21, 28-37. [CrossRef]

24. Zadeh, L.A. Fuzzy Sets. Inf. Control 1965, 8, 338-353. [CrossRef]

25. Zhai, L.Y.; Khoo, L.P.; Zhong, Z.W. Towards a QFD-based expert system: A novel extension to fuzzy QFD methodology using rough set theory. Expert Syst. Appl. 2010, 37, 8888-8896. [CrossRef]

26. Li, G.-D.; Yamaguchi, D.; Nagai, M. A grey-based decision-making approach to the supplier selection problem. Math. Comput. Modell. 2007, 46, 573-581. [CrossRef]

27. Tsai, H.-C.; Hsiao, S.-W.; Hung, F.-K. An image evaluation approach for parameter-based product form and color design Comput.-Aided Des. 2006, 38, 157-171. [CrossRef]

28. Hsiao, S.-W.; Lee, C.-H.; Chen, R.-Q.; Yen, C.-H. An intelligent system for fashion colour prediction based on fuzzy C-means and gray theory. Color Res. Appl. 2016, 42, 273-285. [CrossRef]

29. Lee, Y.-C.; Huang, S.-Y. A new fuzzy concept approach for Kano's model. Expert Syst. Appl. 2009, 36, 4479-4484. [CrossRef]

30. Li, Z.; Tian, Z.G.; Wang, J.W.; Wang, W.M.; Huang, G.Q. Dynamic mapping of design elements and affective responses: A machine learning based method for affective design. J. Eng. Des. 2018, 29, 358-380. [CrossRef]

31. Wang, W.M.; Li, Z.; Tian, Z.G.; Wang, J.W.; Cheng, M.N. Extracting and summarizing affective features and responses from online product descriptions and reviews: A Kansei text mining approach. Eng. Appl. Artif. Intell. 2018, 73, 149-162. [CrossRef]

32. Hsiao, Y.-H.; Chen, M.-C.; Liao, W.-C. Logistics service design for cross-border E-commerce using Kansei engineering with text-mining-based online content analysis. Telemat. Inform. 2017, 34, 284-302. [CrossRef]

33. Chin, S.; Kim, K.-Y. Facial configuration and BMI based personalized face and upper body modeling for customer-oriented wearable product design. Comput. Ind. 2010, 61, 559-575. [CrossRef]

34. Jiao, Y.; Qu, Q.-X. A proposal for Kansei knowledge extraction method based on natural language processing technology and online product reviews. Comput. Ind. 2019, 108, 1-11. [CrossRef]

35. Jin, J.; Ji, P.; Liu, Y.; Johnson Lim, S.C. Translating online customer opinions into engineering characteristics in QFD: A probabilistic language analysis approach. Eng. Appl. Artif. Intell. 2015, 41, 115-127. [CrossRef]

36. Wang, H.; Wang, W. Product weakness finder: An opinion-aware system through sentiment analysis. Ind. Manag. Data Syst. 2014, 114, 1301-1320. [CrossRef]

37. Xiang, Z.; Schwartz, Z.; Gerdes, J.H.; Uysal, M. What can big data and text analytics tell us about hotel guest experience and satisfaction? Int. J. Hosp. Manag. 2015, 44, 120-130. [CrossRef] 
38. Nagamachi, M.; Okazaki, Y.; Ishikawa, M. Kansei engineering and application of the rough sets model. Proc. Inst. Mech. Eng. Part I J. Syst. Control Eng. 2006, 220, 763-768. [CrossRef]

39. Ghorbani, M.; Mohammad Arabzad, S.; Shahin, A. A novel approach for supplier selection based on the Kano model and fuzzy MCDM. Int. J. Prod. Res. 2013, 51, 5469-5484. [CrossRef]

40. Bae, J.K.; Kim, J. Product development with data mining techniques: A case on design of digital camera. Expert Syst. Appl. 2011, 38, 9274-9280. [CrossRef]

41. Wang, C.-H. Integrating Kansei engineering with conjoint analysis to fulfil market segmentation and product customisation for digital cameras. Int. J. Prod. Res. 2015, 53, 2427-2438. [CrossRef]

42. Stavrakos, S.K.; Ahmed-Kristensen, S.; Goldman, T. Using archetypes to create user panels for usability studies: Streamlining focus groups and user studies. Appl. Ergon. 2016, 56, 108-116. [CrossRef]

43. Wang, C.-H.; Wang, J. Combining fuzzy AHP and fuzzy Kano to optimize product varieties for smart cameras: A zero-one integer programming perspective. Appl. Soft Comput. 2014, 22, 410-416. [CrossRef]

44. Wang, T.; Zhou, M. A method for product form design of integrating interactive genetic algorithm with the interval hesitation time and user satisfaction. Int. J. Ind. Ergon. 2020, 76, 102901. [CrossRef]

45. Wang, C.-H. Incorporating the concept of systematic innovation into quality function deployment for developing multi-functional smart phones. Comput. Ind. Eng. 2017, 107, 367-375. [CrossRef]

46. Hsiao, S.-W.; Chiu, F.-Y.; Lu, S.-H. Product-form design model based on genetic algorithms. Int. J. Ind. Ergon. 2010, 40, 237-246. [CrossRef]

47. Shi, F.; Sun, S.; Xu, J. Employing rough sets and association rule mining in KANSEI knowledge extraction. Inf. Sci. 2012, 196, 118-128. [CrossRef]

48. Lin, L.-Z.; Yeh, H.-R.; Wang, M.-C. Integration of Kano's model into FQFD for Taiwanese Ban-Doh banquet culture. Tour. Manag. 2015, 46, 245-262. [CrossRef]

49. Nagpal, G.; Uddin, M.; Kaur, A. Grey Relational Effort Analysis Technique Using Regression Methods for Software Estimation. Int. Arab J. Inf. Technol. 2014, 11, 437-446.

50. Wei, Y. Form Factors of Modeling Language Under Different Color Schemes with Grey Relational Analysis Based on Entropy Method. Int. J. Pattern Recognit. Artif. Intell. 2019, 33, 1950011. [CrossRef]

51. Hsiao, S.-W.; Lin, H.-H.; Ko, Y.-C. Application of Grey Relational Analysis to Decision-Making during Product Development. EURASIA J. Math. Sci. Technol. Educ. 2017, 13, 2581-2600. [CrossRef]

52. Lai, H.-H.; Lin, Y.-C.; Yeh, C.-H. Form design of product image using grey relational analysis and neural network models. Comput. Oper. Res. 2005, 32, 2689-2711. [CrossRef]

53. Tzeng, G.-H.; Huang, J.-J. Multiple Attribute Decision Making: Methods and Applications; CRC Press: Bota Raton, FL, USA, 2011.

54. Chen, C.-T.; Lin, C.-T.; Huang, S.-F. A fuzzy approach for supplier evaluation and selection in supply chain management. Int. J. Prod. Econ. 2006, 102, 289-301. [CrossRef]

55. Şengül, Ü.; Eren, M.; Eslamian Shiraz, S.; Gezder, V.; Şengül, A.B. Fuzzy TOPSIS method for ranking renewable energy supply systems in Turkey. Renew. Energy 2015, 75, 617-625. [CrossRef]

56. Aydogan, E.K. Performance measurement model for Turkish aviation firms using the rough-AHP and TOPSIS methods under fuzzy environment. Expert Syst. Appl. 2011, 38, 3992-3998. [CrossRef]

57. Wang, C.-H. Incorporating customer satisfaction into the decision-making process of product configuration: A fuzzy Kano perspective. Int. J. Prod. Res. 2013, 51, 6651-6662. [CrossRef]

58. Jolai, F.; Yazdian, S.A.; Shahanaghi, K.; Azari Khojasteh, M. Integrating fuzzy TOPSIS and multi-period goal programming for purchasing multiple products from multiple suppliers. J. Purch. Supply Manag. 2011, 17, 42-53. [CrossRef]

59. Ravi kumar, V.; Raghuveer, K. Web User Opinion Analysis for Product Features Extraction and Opinion Summarization. Int. J. Web Semant. Technol. 2012, 3, 69-82. [CrossRef]

60. Sagara, T.; Hagiwara, M. Natural language neural network and its application to question-answering system. Neurocomputing 2014, 142, 201-208. [CrossRef]

61. Liu, B. Sentiment Analysis and Opinion Mining. Synth. Lect. Hum. Lang. Technol. 2012, 5, 1-167. [CrossRef]

62. Yadollahi, A.; Shahraki, A.G.; Zaiane, O.R. Current State of Text Sentiment Analysis from Opinion to Emotion Mining. ACM Comput. Surv. 2017, 50, 1-33. [CrossRef]

63. Mikolov, T.; Chen, K.; Corrado, G.; Dean, J. Efficient Estimation of Word Representations in Vector Space. arXiv 2013, arXiv:1301.3781.

64. Chuan, C.-H.; Agres, K.; Herremans, D. From context to concept: Exploring semantic relationships in music with word2vec. Neural Comput. Appl. 2020, 32, 1023-1036. [CrossRef]

65. Rong, X. Word2vec Parameter Learning Explained. arXiv 2016, arXiv:1411.2738.

66. Zhang, W.; Yoshida, T.; Tang, X. A comparative study of TF-IDF, LSI and multi-words for text classification. Expert Syst. Appl. 2011, 38, 2758-2765. [CrossRef]

67. Zhang, F.; Yang, M.; Liu, W. Evaluation of automobile form design based on fuzzy TOPSIS. Comput. Integr. Manuf. Syst. 2014, 20, 276-283.

68. Atkinson, D.; Baurley, S.; Petreca, B.B.; Berthouze, N.B.; Watkins, P. The tactile triangle: A design research framework demonstrated through tactile comparisons of textile materials. J. Des. Res. 2016, 14, 142-170. [CrossRef] 
69. Torri, L.; Dinnella, C.; Recchia, A.; Naes, T.; Tuorila, H.; Monteleone, E. Projective Mapping for interpreting wine aroma differences as perceived by naïve and experienced assessors. Food Qual. Prefer. 2013, 29, 6-15. [CrossRef]

70. Tani, Y.; Nagai, T.; Koida, K.; Kitazaki, M.; Nakauchi, S. Experts and novices use the same factors-But differently-To evaluate pearl quality. PLoS ONE 2014, 9, e86400. [CrossRef]

71. Van Paasschen, J.; Bacci, F.; Melcher, D.P. The Influence of Art Expertise and Training on Emotion and Preference Ratings for Representational and Abstract Artworks. PLOS ONE 2015, 10, e0134241.

72. Bahn, S.; Lee, C.; Nam, C.S.; Yun, M.H. Incorporating affective customer needs for luxuriousness into product design attributes. Hum. Factors Ergon. Manuf. 2009, 19, 105-127. [CrossRef]

73. Kanai, H.; Morishima, M.; Nasu, K.; Nishimatsu, T.; Shibata, K.; Matsuoka, T. Identification of principal factors of fabric aesthetics by the evaluation from experts on textiles and from untrained consumers. Text. Res. J. 2011, 81, 1216-1225. [CrossRef]

74. Kim, W.; Lee, Y.; Lee, J.H.; Shin, G.W.; Yun, M.H. A comparative study on designer and customer preference models of leather for vehicle. Int. J. Ind. Ergon. 2018, 65, 110-121. [CrossRef]

75. Poulami, D.; Debnath, B.; Kumar, B.S.; Tai-Hoon, K. Person Identification through IRIS Recognition. Int. J. Secur. Appl. 2009, 3 , $163-178$. 